WORKING PAPER · NO. 2020-128

Fifty Shades of QE:

Conflicts of Interest in Economic Research

Brian Fabo, Martina Jančoková, Elisabeth Kempf, and Lubos Pastor

OCTOBER 2020

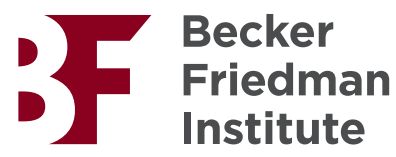




\title{
Fifty Shades of QE: \\ Conflicts of Interest in Economic Research *
}

\author{
Brian Fabo ${ }^{1}$, Martina Jančoková ${ }^{2}$, Elisabeth Kempf $^{3,5}$, Ľuboš Pástor ${ }^{1,3,4,5}$ \\ ${ }^{1}$ National Bank of Slovakia \\ ${ }^{2}$ European Central Bank \\ ${ }^{3}$ University of Chicago Booth School of Business \\ ${ }^{4} N B E R, U S A$ \\ ${ }^{5}$ CEPR, United Kingdom
}

October 14, 2020

\begin{abstract}
Central banks sometimes evaluate their own policies. To assess the inherent conflict of interest, we compare the research findings of central bank researchers and academic economists regarding the macroeconomic effects of quantitative easing (QE). We find that central bank papers report larger effects of QE on output and inflation. Central bankers are also more likely to report significant effects of QE on output and to use more positive language in the abstract. Central bankers who report larger QE effects on output experience more favorable career outcomes. A survey of central banks reveals substantial involvement of bank management in research production.
\end{abstract}

JEL Classification: A11, E52, E58, G28

${ }^{*}$ The views in this paper are those of the authors and do not represent the views of the European Central Bank, the National Bank of Slovakia, or any other institution. Pástor is a member of the bank board of the National Bank of Slovakia. We are grateful for comments from Wenxin Du, Mara Faccio, Pavel Gertler, Sujit Kapadia, Anil Kashyap, Luc Laeven, Ľudovít Ódor, Raghuram Rajan, Kasper Roszbach, and Martin Šuster, as well as to seminar participants at the European Central Bank, National Bank of Slovakia, Purdue University, Toulouse School of Economics, the University of Chicago, the University of Geneva, and the University of Miami. We are also grateful to Livia Amato, Yuliia Kazmina, Fulin Li, Eva Štulrajterová and, especially, Bianca He for excellent research assistance. This research was funded in part by the Fama-Miller Center for Research in Finance at Chicago Booth. 


\section{Introduction}

Accurate information is important in achieving efficient outcomes. However, some suppliers of information have other incentives besides accuracy. For example, financial analysts trade off incentives to provide accurate information to investors against incentives to earn revenue from the companies they evaluate. ${ }^{1}$ Similarly, information produced by media outlets may be tainted by their incentives to generate ad revenue (Reuter and Zitzewitz (2006)), advance political interests (Groseclose and Milyo (2005)), or conform with consumers' prior expectations (Mullainathan and Shleifer (2005), and Gentzkow and Shapiro (2010)).

Like journalists and financial analysts, scientists have incentives that could potentially bias their research output. For example, scientists sponsored by industry may act in the interests of their sponsors. This conflict of interest has been extensively documented in biomedical research, where financial relationships between researchers and the pharmaceutical industry are widespread. Many studies find that industry-sponsored biomedical research tends to draw conclusions favorable to the sponsor. ${ }^{2}$ Mechanisms through which this prosponsor bias operates range from drug companies' influence over research design to their suppression of adverse research results, all the way to intimidating researchers and threatening legal action (e.g., Collier and Iheanacho (2002); Sage (2007)).

We know far less about conflicts of interest in economics, but they do exist. Economists working in industry have an incentive to publish research advancing the interests of their employers. So do academic economists moonlighting as industry consultants. Academics do not always disclose their private financial affiliations (Carrick-Hagenbarth and Epstein (2012)). Zingales (2013) discusses how academic research could be corrupted by economists' outside employment opportunities or their desire to gain access to proprietary data.

In this paper, we highlight a conflict of interests that has received little attention: that of central bank economists conducting research that evaluates central bank policies. Such research is common and widely cited. ${ }^{3}$ The problem is that a central bank economist may have an incentive to find central bank policies to be effective, for several reasons.

\footnotetext{
${ }^{1}$ There is a large literature on the conflicts of interest leading to biases in equity analysts' earnings forecasts and stock recommendations (e.g., Michaely and Womack (1999); Malmendier and Shanthikumar (2007), and Hong and Kacperczyk (2010)). Many studies also analyze the conflicts of interest faced by credit rating agencies, which get paid by the companies they evaluate (e.g., Mathis et al. (2009); Bolton et al. (2012); Griffin and Tang (2012), and Jiang et al. (2012)).

${ }^{2}$ See, for example, Bekelman et al. (2003); Lexchin et al. (2003); Sismondo (2008).

${ }^{3}$ For example: "The good news is that, by most accounts, QE appears to have succeeded at boosting growth and lifting inflation. Martin Weale, a member of the BoE's interest-rate setting Monetary Policy Committee, found asset purchases worth $1 \%$ of national income boosted UK gross domestic product by about $0.18 \%$ and inflation by $0.3 \%$. A study by John Williams, president of the San Francisco Federal Reserve, concluded that asset purchases had reduced the US unemployment rate by 1.5 percentage points by late 2012 and helped the economy avoid deflation." The Financial Times (2015).
} 
First, the economist may worry that the nature of her findings could affect her employment status or rank. Is she less likely to get promoted if her findings dent the bank's reputation? Could she get fired? We are not aware of any evidence of central banks punishing their employees in this manner. Yet this career concern is relevant even if it is completely unfounded as long as the economist assigns a nonzero probability to such a threat. This channel could operate at multiple levels because not only researchers but also their superiors want to get promoted. A head of research eyeing a promotion, or fearing a demotion, may be reluctant to defend a subordinate's inconvenient findings in front of the bank's board. The head may find it easier to suggest to the subordinate that a different econometric specification, or at least a differently-worded abstract, would make the paper stronger.

Second, the economist may be unsure whether her research will see the light of day. Bank management could in principle block the release of studies that find the bank's own policy to be ineffective, or to have undesirable side effects. A recent example, albeit from a different public institution, is the controversial release of Andersen et al. (2020). That study finds that World Bank payouts of foreign aid are followed by jumps in the recipient countries' deposits in financial havens, suggesting leaks to the pockets of the countries' elites. According to media reports, after the study passed an internal peer review at the World Bank, it was "blocked by higher officials." 4 After a substantial delay, the study was eventually released in February 2020. Its release occurred within days of the departure of the World Bank's chief economist, an academic, after only 15 months in the job.

Third, the economist may believe a priori that the bank's policies are effective, and she may favor evidence supporting her prior. In principle, researchers who believe in the power of policy interventions could self-select into policy institutions such as central banks. Moreover, their priors could be reinforced during the research process, either through the well known confirmation bias (Nickerson (1998)) or through the feedback researchers receive from their central bank colleagues, whose priors may be similar.

Fourth, the economist may care about the bank's reputation. She may dislike conclusions that could be perceived as damaging, preferring conclusions that validate the bank's actions. Finally, the economist may care about her own reputation if she is senior enough to have participated in the formation of the bank's policy. For example, in his presidential address to the American Economic Association, Bernanke (2020) offers a strong endorsement of

\footnotetext{
${ }^{4}$ See "The World Bank loses another chief economist", The Economist (2020). Years earlier, in their broad evaluation of World Bank research, Banerjee et al. (2006) argue: "Internal research that was favorable to Bank positions was given great prominence, and unfavorable research ignored... there was a serious failure of the checks and balances that should separate advocacy and research. The panel endorses the right of the Bank to strongly defend and advocate its own policies. But when the Bank leadership selectively appeals to relatively new and untested research as hard evidence that its preferred policies work, it lends unwarranted confidence to the Banks' prescriptions. Placing fragile selected new research results on a pedestal invites later recrimination that undermines the credibility and usefulness of all Bank research."
} 
unconventional monetary policy tools. Given his unique experience as an academic-turnedtop-policymaker, Ben Bernanke is exceptionally qualified to provide an accurate assessment of the effectiveness of these tools. At the same time, these tools are an important part of his legacy as they were adopted while he was Fed Chair.

Each of these five reasons could in principle induce a bias akin to the pro-sponsor bias in biomedical research. In fact, the bias could be even more severe for central bankers. While academic medical researchers are merely sponsored by industry, central bank economists are directly employed by central banks. Central banks evaluating their own policies is not unlike pharmaceutical firms evaluating their own drugs. Both have skin in the game. The conflict of interest is particularly acute for central banks that view their research output regarding their own policy as part of the policy itself, because by releasing a study supportive of this policy, they could potentially enhance the policy's effectiveness. On the other hand, alleviating this conflict is the strong desire of central banks to produce objective research.

Academic economists who evaluate central bank policies do not have skin in the game, but they have their own incentive to find strong results because they face the pressure to publish. Academics' career concerns are commonly summarized as "publish or perish." These concerns seem weaker for central bankers, who can often substitute policy work for journal publications. The need to publish creates a pressure for academics to find significant results because of the well-known publication bias: journals are more likely to publish positive results than negative ones (e.g., Fanelli $(2010 a)$ ). Both central bankers and academics thus have their own incentives to find significant effects when evaluating bank policy. Whose incentives are stronger is ultimately an empirical question.

In this paper, we compare the findings of central bank researchers and academics regarding the effectiveness of unconventional monetary policy. In the aftermath of the 2008 financial crisis, central banks around the world have deployed new policy tools to address the challenges posed by the crisis. These policy tools include quantitative easing (QE), which represents large-scale purchases of longer-term financial assets such as government debt, as well as policies such as forward guidance and long-term refinancing operations. The effectiveness of these tools has been a subject of intense debate in both academic and policy circles, with a significant part of the literature originating in central banks (Martin and Milas (2012)). The debate has become even more salient since the arrival of the COVID-19 pandemic, which has spawned renewed interest in these tools among policymakers.

We construct a dataset comprising 54 studies that analyze the effects of unconventional monetary policy ("QE" for short) on output or inflation in the U.S., UK, and the euro area. For each study, we record its baseline estimates of the effects of QE on the level of GDP and the price level, along with their significance. We also collect a variety of other study- 
specific information, such as publication status and methodology used, as well as detailed biographical information of the 116 different authors. We then compare the findings of studies written by central bankers with those written by academics.

We find that central bank papers report systematically larger effects of QE on both output and inflation. Central bank papers are also more likely to report QE effects on output that are significant, both statistically and economically. For example, while all of the central bank papers report a statistically significant QE effect on output, only half of the academic papers do. Central bank papers are more likely to not disclose the width of the confidence interval, and also to use dynamic stochastic general equilibrium (DSGE) models rather than vector autoregression (VAR) models in their estimation. In addition, central bank papers use more favorable language in their abstracts: they use more positive adjectives and, to a lesser extent, fewer negative adjectives compared to academic papers. Overall, central bank papers find $\mathrm{QE}$ to be more effective than academic papers do.

To see whether this result could be driven by career concerns, we relate the research findings of central bank economists to their subsequent career outcomes. We collect employment histories for all central bank authors and convert their job titles to numerical ranks on a sixpoint scale. For each author-paper pair, we measure the author's subsequent career outcome by the first change in the author's rank following the paper's first public release. We find that authors whose papers report larger effects of QE on output experience more favorable career outcomes. A one standard deviation increase in the estimated effect is associated with a career improvement of about half a rank, such as moving halfway from Economist to Senior Economist. This evidence is consistent with career concerns.

These concerns appear to be stronger for senior central bank economists because for them, the relation between career outcomes and the estimated QE effects is stronger. Motivated by this finding, we look whether our main result - a gap between the findings of central bankers and academics regarding the effectiveness of QE - is larger for papers whose authors are more senior. We find that it is, though the relation is only marginally significant. Our results are consistent with the hypothesis that senior central bankers report larger effects of QE because they are more incentivized to do so.

Not all central bankers face the same incentives. Top management of the German Bundesbank has taken a critical view of QE, especially in the context of the European Central Bank (ECB). Former Bundesbank officials Axel Weber and Jürgen Stark reportedly quit their ECB positions in protest over QE, and the current Bundesbank president, Jens Weidmann, has also publicly opposed it. Mindful of their bosses' views, Bundesbank researchers could potentially face career concerns very different from those of their colleagues at other central banks. Indeed, we show that studies co-authored by Bundesbank employees find QE 
to be less effective at raising output compared to academic studies. While this evidence is weak statistically, it is consistent with managerial influence on research outcomes.

To shed more light on this influence, we survey heads of research at the world's leading central banks. We have received responses from 24 central banks employing over 750 research economists in total. These responses reveal heterogeneous but substantial involvement of bank management in research production. In most banks, management participates in the selection of research topics, typically by negotiating with the researcher. Direct topic assignments occur "sometimes" ("often") in $50 \%$ (21\%) of the responding banks. In most banks, research papers are reviewed by management prior to public distribution; such reviews happen "always" ("often") in 38\% (21\%) of the responding banks. Management also approves papers for public distribution: typically by the head of research ("always" in $67 \%$ of the banks), but sometimes also by the bank board (at least "sometimes" in $33 \%$ of the banks). This evidence reveals substantial managerial involvement in research production. This involvement surely includes helpful guidance, and possibly more. Unlike central bankers, academics face little if any managerial interference in their research.

A by-product of our analysis is a meta-analysis of the macroeconomic effects of QE. Averaging across all 54 studies and standardizing each QE shock to $1 \%$ of the country's preQE GDP, QE increases the level of output (the price level) by $0.24 \%(0.19 \%)$ at the peak. The average cumulative effect on output (prices) is $58 \%(63 \%)$ of the peak effect. About $88 \%(84 \%)$ of studies estimate effects on output (prices) that are statistically significant. Across the three regions studied, QE is the most effective in the U.S., in terms of raising both output and the price level.

Our study is related to the literature inspecting the credibility of scientific research (e.g., Ioannidis (2005); Fanelli (2009), and Fanelli et al. (2017)). Economic research has not escaped this scrutiny. In an early critique, Leamer (1983) argues that empirical economics is vulnerable to biases and produces fragile results. The publication bias mentioned earlier seems particularly strong in economics (e.g., De Long and Lang (1992); Fanelli (2010b, 2012); Doucouliagos and Stanley (2013)). Some authors do not submit null findings (Franco, Malhotra and Simonovits (2014)); others inflate the values of just-rejected tests by choosing "significant" specifications (Brodeur et al. (2016)). Ioannidis et al. (2017) argue that many results reported in the economic literature are exaggerated. Other problems include scientific misconduct (Bailey et al. (2001); List et al. (2001)) and the lack of a reproducibility culture, with the associated inability to replicate economic findings (Ioannidis and Doucouliagos (2013), and Christensen and Miguel (2018)). It also seems problematic that reported estimates of policy-relevant parameters, such as fiscal multipliers, reflect the authors' national backgrounds and political orientation (Asatryan et al. (2020); Jelveh et al. (2018)). 
Also related is the literature on career concerns, which finds evidence of such concerns for both private- and public-sector workers. ${ }^{5}$ In contrast, there is little work on the incentives of central bankers. That work focuses mostly on the voting members of a central bank's monetary policy committee (e.g., Sibert (2003); Besley et al. (2008); Gerlach-Kristen (2009); Meade and Stasavage (2008); Hansen et al. (2018)). We are not aware of any work on the incentives or biases of central bank research economists.

\section{Data}

We construct a dataset comprising studies of the effects of unconventional monetary policy on two key macroeconomic variables: output and inflation. We aim to cover all articles, published and unpublished, that analyze the policy effects for at least one of three economies: the United States (US), the United Kingdom (UK), and the euro area (EA). For ease of exposition, we refer to these economies, including EA, as "countries." We focus on articles containing a quantitative analysis, either model-based or fully empirical, of the effects on output, inflation, or both. We do not consider papers focusing on the effects of policy on asset prices unless they also analyze its effects on output or inflation.

To identify the papers, we manually search for 40 relevant terms in the Google Scholar and Repec IDEAS databases. All search terms are listed in the Internet Appendix, which is available on the authors' websites. Our search covers not only QE but also other unconventional monetary policy tools that operate through central bank balance sheets, such as long-term refinancing operations. Since about $80 \%$ of the papers in our sample study QE, we refer to all papers as "QE" studies, for brevity. We conducted the search in July and August of 2019, covering all articles publicly distributed prior to July 2018. For each search term, we examine the first ten pages of search results in both portals as well as all references in the resulting articles. Next, we screen all documents listed in Google Scholar as citing one of the articles obtained in the first step, as well as references therein. Finally, we screen all articles citing the articles added in the second step. We exclude studies not written in English, as well as Master's and Bachelor's theses. We include all other types of articles: journal publications, working papers, book chapters, and policy papers. We always use the published version of the article if it is available at the time of our search, and otherwise the most recent version of the article available online. Our final sample consists of 54 papers written by 137 authors, 116 of whom are unique. All 54 papers are listed in the Internet

\footnotetext{
${ }^{5}$ These workers include corporate executives (Warner et al. (1988), and Weisbach (1988)), equity analysts (Hong et al. (2000), and Hong and Kubik (2003)), credit analysts (Cornaggia et al. (2016), and Kempf (2020)), professional investors (Chevalier and Ellison (1999)), sales workers (Benson et al. (2019)), banking regulators (Lucca et al. (2014)) and federal government employees (Blanes i Vidal et al. (2012)).
} 
Appendix.

For each article, we collect information on the year of first public distribution, year of journal publication (if any), publication outlet, authors' names, and the methodology used (e.g., a DSGE or VAR model). We obtain impact factors and article influence scores from Clarivate Analytics Web of Science for the year of the article's publication. We record the effects of QE on the level of GDP and the price level as implied by the authors' baseline model. We distinguish four estimated effects: (i) the peak effect of the QE program studied (Total Peak Effect); (ii) the cumulative effect of QE, defined as the effect at the end of the time period studied by the authors (Total Cumulative Effect); (iii) the peak effect after standardizing the QE shock size to 1\% of GDP (Standardized Peak Effect); and (iv) the cumulative effect after the same standardization (Standardized Cumulative Effect). We describe the construction of all four variables in more detail in Section 2.2.

We also record the authors' assessments of the statistical and economic significance of their estimated effects of QE on output and inflation. Whenever available, we use the authors' own verbal assessment of statistical significance. If unavailable, we infer statistical significance from confidence intervals reported in the corresponding figure or table, using the peak effect. We also record the confidence level used by authors to assess significance (95\%, 90\%, or $68 \%)$. When statistical significance is not discussed and no standard errors or $p$-values are reported, we set the variable to missing. For economic significance, we always use the authors' own verbal assessment. For example, if a study states the effect of QE is "negligible", we code economic significance as zero; if the effect is "sizable", we code economic significance as one. For all ambiguous cases, we code economic significance as 0.5. Examples include studies stating that the effect of QE is positive upon impact but disappears quickly, or that it is positive but very sensitive to model specification. When economic significance is not discussed, we set it to missing.

To analyze a paper's tone, we focus on the paper's abstract and conclusion, which tend to summarize the main findings in a non-technical manner. As we are not aware of any lexical sentiment model trained on the economic research literature, we create our own lexicon. We consider adjectives such as "significant," "sizable," and "large" as positive, conveying the message that QE is effective, and adjectives such as "small," "negligible," and "weak" as negative, conveying the opposite message. The full list of positive and negative adjectives is in Table A.1. We compute the shares of positive and negative adjectives out of all adjectives, for both the abstract and the conclusion. We also compute a "sentiment score" as the share of positive adjectives minus the share of negative adjectives.

Finally, we manually collect information on the employment history, job titles, and educational background for the 116 authors by using online searches and information from 
public LinkedIn pages. To determine author affiliation, we use the author's main employer at the time of the paper's first public distribution, as determined by our search in the summer of 2019. We categorize all authors whose primary affiliation is a central bank as "central bankers." We classify authors from the Bank of International Settlements (BIS) as 0.5 central bankers due to the close ties between the BIS and the central banking community. ${ }^{6}$ We refer to all other authors simply as "academics." We disclose our full paper-level dataset in the Internet Appendix.

\subsection{Summary Statistics}

Figure 1 plots selected summary statistics at the paper level, by year and country studied. The papers in our sample appear in each year between 2010 and 2018. They do not have to contain estimates for both output and inflation, but about $90 \%$ of them do. The share of central-bank-affiliated authors averages a little above one half. All variables are distributed fairly evenly across countries, with the euro area receiving a bit more attention.

Figure 2 focuses on the authors. Central banks employing the largest numbers of authors in our sample are the Bank of England, national central banks in the euro area, the ECB, and the Federal Reserve. Academics are employed mostly at universities in Europe (18), UK (10), and the U.S. (9). Most of the authors have earned their PhD degrees at prestigious universities in the U.S. and UK.

Figure 3 reports the number of articles by QE program studied, separately for articles with and without at least one central bank author. We observe substantial sorting of central bankers and academics into different QE programs studied. For example, whereas QE1 in the UK is commonly studied by both central bankers and academics, APP in the euro area and LSAP1 in the U.S. are predominantly studied by central bankers.

Table 1 provides additional descriptive statistics at both the paper level (Panel A) and the author-paper level (Panel B). The average article in our sample is written by 2.5 authors and it studies the effects of QE in 1.3 countries. More than $57 \%$ of the articles are published in peer-reviewed journals. The average impact factor of those journals at the time of the respective paper's publication is 1.42 . $35 \%$ of the papers use DSGE models. $60 \%$ of the authors in our sample are primarily affiliated with a central bank. $17 \%$ of the authors are women and $89 \%$ hold a $\mathrm{PhD}$ degree. The average author experience (i.e., the number of years since obtaining the highest educational degree) is 11 years. At the time of the paper's first public distribution, the average number of years since the author's last career update

\footnotetext{
${ }^{6}$ In the Internet Appendix, we show that our main results are robust to classifying BIS authors as full central bankers. They are also robust to classifying researchers at the International Monetary Fund and the World Bank as 0.5 central bankers, although such an alternative classification seems harder to justify.
} 
(i.e., employment or job title change) is 3.9 years.

\subsection{The Effects of QE on Output and Inflation}

For each paper and country studied, we record the estimated effects of QE on output (i.e., real GDP or industrial production) and inflation (i.e., CPI) based on the authors' baseline specification. As a rule, we record the effects on the level - the level of output and the price level. Letting $Y$ denote the actual level of the outcome variable (i.e., with QE) and $\hat{Y}$ denote its counterfactual level (i.e., without $\mathrm{QE}$ ), we are interested in the percentage difference, $(Y-\hat{Y}) / \hat{Y}$. If the paper reports the effect of QE on the level of output or prices, we record the peak and cumulative effects as displayed in Figure 4. If the paper reports only the effects on the growth rate, we sum up the individual growth estimates to determine the impact on the level. We describe the details of this conversion and list the estimated effects for each paper-country pair in our sample in the Internet Appendix.

We focus on the effect most prominently advertised in the paper, ignoring estimates from robustness checks, alternative specifications, and extensions. We standardize the effects to a common shock size equal to $1 \%$ of the respective country's GDP around the time QE was first introduced. For the U.S. and UK, we use 1\% of the annualized 2009 Q1 GDP, consistent with Weale and Wieladek (2016). For the euro area, whose asset purchase programs started in 2015 Q1, we use 1\% of the annualized 2015 Q1 GDP. We obtain GDP estimates from the FRED database. Performing the standardization also requires the size of aggregate asset purchases for each QE program. We report our estimates of these sizes in the Internet Appendix. Following Weale and Wieladek (2016), we include Treasury purchases for the U.S. programs, and all securities purchased under the Asset Purchasing Facility for the UK programs. For the euro area, program size includes all securities purchased under the Asset Purchase Program, because asset-backed securities are a small fraction of the overall program size. ${ }^{7}$

Table 2 reports the means, medians, and standard deviations of the estimated effects of QE on the levels of output and prices, for the full sample as well as by country. For the full sample, the average (median) article in our sample estimates that QE increases output by $1.57 \%(1.25 \%)$ at the peak. Standardized to a QE shock equivalent to $1 \%$ of GDP, the average (median) peak effect on output is $0.24 \%(0.16 \%)$. Still focusing on standardized effects, the average cumulative effect on output corresponds to $58 \%$ of the average peak effect, indicating that a substantial part of the peak effect vanishes by the end of the period studied. The standard deviation of the within-country estimates is large, comparable to the mean. There is also substantial heterogeneity in the effectiveness of QE across the three

\footnotetext{
${ }^{7}$ See https://www.ecb.europa.eu/mopo/implement/omt/html/index.en.html.
} 
countries. Focusing on the standardized effects, which are easier to compare across countries due to differences in QE program sizes, QE is most effective at raising output in the U.S., followed by the EA and UK.

As for inflation, the average (median) study finds that QE raises the price level by $1.42 \%$ $(0.93 \%)$ at the peak. Standardized to a QE shock size of $1 \%$ of GDP, the average (median) effect on the price level is $0.19 \%(0.11 \%)$. The cumulative effect is again considerably smaller. Across the three countries, QE is again most effective in the U.S. Finally, the vast majority of studies conclude that the estimated effects on output and inflation are positive and statistically significant.

Overall, Table 2 shows that the consensus of the existing literature is that QE has a positive and significant effect on both output and prices. This finding is consistent with prior reviews of this literature (e.g., Dell'Ariccia et al. (2018)). However, the table also reveals substantial heterogeneity in point estimates for both outcome variables. Understanding whether some of this heterogeneity is systematically related to the institutional environment in which authors operate is the goal of the following sections.

\section{Research Outcomes and Central Bank Affiliation}

This section provides a systematic comparison of the research findings of central bankers and academics regarding the effectiveness of QE. These findings include the estimated effects of QE on output and inflation, the statistical and economic significance of these effects, and the tone of the language used to summarize the paper's results.

\subsection{The Effect of QE on Output}

Figure 5 reports histograms for the estimated effects of QE on the output level, separately for studies with at least one central bank author ("CB") and those with no such authors ("Not CB"). The four panels correspond to the four measures introduced previously. For all of them, the distributions of central bank papers are shifted visibly to the right, indicating that such papers find systematically larger effects of QE on output.

The same result follows from Panel A of Table 3, which compares the means and medians of the estimated effects of QE on output across papers with and without at least one central bank author. Both types of papers find QE to be successful at raising output, on average, but central bank papers find substantially larger effects. This is true based on both means and medians, indicating that the gap is not driven by outliers. ${ }^{8}$

\footnotetext{
${ }^{8}$ The outliers in Figure 5 do not seem to be low-quality papers, at least judging by their publication success. In fact, among the five papers finding the largest effects on output, the publication rate is $100 \%$.
} 
Table 4 confirms the result based on regression evidence. We regress the estimated output effect on the share of central bank authors, $C B$ Affiliation, defined as the share of authors who are affiliated with a central bank at the time of the paper's first public distribution. In the strictest specifications, shown in columns (3) and (6), we also include country fixed effects and controls for the number of authors and average author experience:

$$
y_{i j}=\alpha_{j}+\beta[\mathrm{CB} \text { Affiliation }]_{i}+\gamma^{\prime} X_{i}+\epsilon_{i j}
$$

where $y_{i j}$ is the effect of QE on output estimated by study $i$ for country $j$ 's QE, $\alpha_{j}$ is a fixed effect for the country in which QE takes place, and $X_{i}$ are the two controls. ${ }^{9}$ All variables are defined in Table A.2.

Columns (3) and (6) show that changing the share of central bank authors from zero to $100 \%$ is associated with a 0.723 percentage points larger peak effect and a 0.512 percentage points larger cumulative effect on output (Panel A). These are sizable magnitudes relative to the unconditional means of $1.57 \%$ and $0.87 \%$, respectively, from Table 2 . The results based on standardized effects, reported in Panel B, are also economically large. Going from zero to $100 \%$ central bank authors corresponds to a 0.152 percentage points larger standardized peak effect: an increase by two thirds of the unconditional mean. For the standardized cumulative effect, the difference is 0.122 percentage points, equivalent to $87 \%$ of the unconditional mean. These results show that the differences in research findings observed in Panel A are not due to central bankers studying larger QE programs.

To assess the statistical significance of these results, we report $t$-statistics based on standard errors clustered at the paper level. A potential concern about inference based on cluster-robust standard errors is that the cluster-robust variance estimator converges to the true value as the number of clusters tends to infinity, but we have at most 54 clusters. We thus follow Cameron and Miller (2015) and Cameron et al. (2008) in implementing a wild cluster bootstrap procedure. We report the resulting $p$-values in square brackets. ${ }^{10}$ We generally use these $p$-values, which tend to be more conservative than $t$-statistics, to assess statistical significance. In Panel A of Table 4, the coefficient on CB Affiliation is significant at the $10 \%$ or $5 \%$ level for the peak effect, but it is insignificant for the cumulative effect. In Panel B, the coefficient is significant at the $5 \%$ level in all specifications except for column (3), where it is significant at the $10 \%$ level.

\footnotetext{
${ }^{9}$ Our control for author experience is $\log (3+$ average author experience). We add three because the minimum value of author experience in our sample is -2 (for an author who wrote their paper two years prior to earning a Ph.D.). This way, the log is defined for all observations with non-missing author experience.

${ }^{10}$ Davidson and MacKinnon (2010) and MacKinnon and Webb (2017) show that tests based on wild cluster bootstraps often perform well. We obtain wild bootstrap $p$-values using the post-estimation command boottest developed by Roodman et al. (2019), using Webb weights, assuming the null hypothesis, and using 10,000 replications.
} 


\subsection{The Effect of QE on Inflation}

Figure 6 reports histograms for the estimated effects of QE on the price level, analogous to the histograms for output plotted in Figure 5. Just like for output, the distributions of central bank papers are shifted to the right relative to academic papers, indicating that central bank papers tend to find $\mathrm{QE}$ to be more effective at raising prices. The same conclusion follows from Panel B of Table 3, which compares the means and medians of the estimated effects of QE on inflation across papers with and without central bank authors.

In Table 5 we repeat the analysis from Table 4 , but with a different dependent variable: $y_{i j}$ in equation (1) is now the estimated effect on inflation rather than output. According to Panel A, columns (3) and (6), changing the share of central bank authors from zero to $100 \%$ corresponds to a 1.279 percentage points larger peak effect and a 1.394 percentage points larger cumulative effect on prices. These effects are large relative to the unconditional means of $1.42 \%$ and $0.89 \%$, respectively, from Table 2 . In Panel B, the coefficients on $C B$ Affiliation are 0.201 percentage points for the peak effect and 0.190 percentage points for the cumulative effect. These coefficients are even larger than the corresponding unconditional means. All of the coefficients in Table 5 are statistically significant at the $5 \%$ level.

\subsection{Significance}

Next, we examine the statistical and economic significance of the effects of QE on output and inflation. Our main interest is in whether studies by central bankers and academics differ in their assessments of this significance. One advantage of looking at significance is that it is directly comparable across studies with no need for any standardization or conversion in the construction of the peak and cumulative effects of QE.

Panel A of Figure 7 plots the shares of studies that find a statistically significant effect of QE on output, separately for central bankers and academics. The difference is striking: while half of the academic papers find a significant effect, all of the central bank papers do. The difference in the assessments of economic significance, reported in Panel B, is also visually prominent. Panels $\mathrm{C}$ and D show similar, though less pronounced, patterns for inflation.

Table 6 shows the extent to which these differences are statistically significant and robust to the inclusion of control variables. We estimate the regression specification in equation (1), with $y_{i j}$ redefined to denote either statistical or economic significance, for the effects of QE on either output or inflation. For output (Panel A), the coefficient on CB Affiliation is always positive and significant at the $5 \%$ level, whether the dependent variable is statistical or economic significance. The magnitude of the effect is also large: the estimate in Panel A, column (3), implies that increasing the share of central bank authors from zero to $100 \%$ 
corresponds to a 36.6 percentage points higher likelihood of the study finding a statistically significant effect of QE on output. The magnitude is even larger, 39.9 percentage points, for economic significance of the QE effect on output. For inflation (Panel B), we also find economically large effects, but they are not statistically significant.

\subsection{Alternative Specifications}

We consider various modifications of our baseline regression (1), as analyzed in Sections 3.1 through 3.3. We summarize the results here but report them in the Internet Appendix.

Recall that the main independent variable in regression (1), CB Affiliation, is the fraction of the paper's authors who are affiliated with a central bank. Our results in Tables 4 through 6 hold also when we replace this granular measure by an indicator we call Discrete, which is equal to one if at least one of the authors is affiliated with a central bank or the BIS, and zero otherwise. In addition, we replace $C B$ Affiliation by two zero/one indicators: Mixed, which is equal to one if the share of central-bank-affiliated authors is strictly between zero and one, and Pure $C B$, which equals one if all of the authors are central bankers. We find positive point estimates of the coefficients on both indicators in all 36 specifications considered in Tables 4 through 6. Moreover, the estimated slope on Pure CB exceeds that on Mixed in 33 of the 36 specifications, suggesting that central bankers tend to find larger effects of QE when they have no academic coauthors.

Different central banks may have different research-vetting policies. Motivated by this possibility, we separate central bank authors by the country of the central bank they work for. We replace $C B$ Affiliation in equation (1) by four zero/one indicators: $E A C B$ is equal to one if at least one of the authors is affiliated with the ECB or a national central bank in the euro area, $U K C B$ equals one if at least one author is affiliated with the Bank of England, $U S C B$ equals one if at least one author is affiliated with the Federal Reserve Board or a regional Fed, and Other $C B$ equals one if at least one author is affiliated with another central bank or the BIS. The omitted group is academics. We find positive point estimates of the coefficients on all four indicators, suggesting that our results in Tables 4 to 6 are not driven by authors from any single country. Fed researchers tend to find the largest effects of QE on output, whereas Bank of England researchers tend to find the largest effects on inflation. Euro area central bankers find relatively weak QE effects by central bank standards, largely due to the weaker effects reported by Bundesbank researchers (Section 4.3.1). However, the differences across central banks are not statistically significant.

Taking a different country-by-country perspective, we focus on the country in which QE takes place. We observe that the point estimates of $\beta$ in equation (1) are generally positive for all three countries, though their statistical significance is mixed. Looking at the effects of 
QE on output, the $\beta$ estimate is the largest, and significant, for QE conducted in the U.S. In other words, the gap between the output effects reported by central bankers and academics is largest when they analyze U.S. QE. For the effects of QE on inflation, the $\beta$ estimates are large, and typically significant, in both the U.S. and UK.

Motivated by the strong results we find for the U.S., we dig deeper into them by considering the three main QE programs in the U.S. separately. The point estimates of $\beta$ are positive and large for all three programs, but they are often insignificant because of small sample sizes: we have 12 studies of the output effects of QE1, 12 studies for QE2, and only 4 studies for QE3. The estimates are similar across the three programs, indicating that our results are not driven by any individual U.S. program.

More broadly, we do not control for the specific QE program in our baseline regressions. The choice of which QE program to study is made by the authors so, being endogenous, it is a potential outcome variable of interest. For example, if U.S. QE1 is perceived as being more effective than QE2 or QE3, an author aiming to report stronger QE effects can choose to analyze the first round of QE rather than its later rounds. Nevertheless, we also report results when controlling for QE program dummies, thereby comparing central bankers and academics analyzing the same QE program. For papers studying more than one QE program, more than one dummy is switched on at the same time. We find that adding QE program dummies tends to reduce the statistical significance of the results: the estimate of $\beta$ is significant in 17 specifications at the $5 \%$ level, and in 22 specifications at the $10 \%$ level, out of all 36 specifications considered in Tables 4 through 6 (for comparison, in those tables, the $\beta$ estimate is significant in 25 specifications at the $5 \%$ level, and in 28 specifications at the $10 \%$ level). The decline in statistical significance is unsurprising because we can only consider QE programs studied by at least two papers. Nevertheless, even with QE program dummies, the point estimates have the same signs as their counterparts in Tables 4 through 6 in all specifications, and their magnitudes are economically significant.

Our baseline regressions do not control for the model chosen by the authors because model choice is endogenous, just like the choice of the QE program to study. However, our main results are largely unaffected if we control for the model chosen (DSGE, VAR, or other). Out of the 36 specifications considered in Tables 4 through 6 , we continue to find statistical significance at the 5\% (10\%) level in 23 (29) specifications. Moreover, the magnitudes of the estimated $\beta$ coefficients become larger in 27 specifications and smaller only in 9 specifications. Hence, although we prefer not to control for model choice, given its endogeneity, our main results are robust to such controls.

We further explore whether central bankers are more optimistic when they study QE by their own central bank as opposed to some other central bank. To do so, we include paper 
fixed effects, thereby comparing the effects of $\mathrm{QE}$ in different countries as estimated by the same paper. We do not find any noteworthy support for the hypothesis. Naturally, with paper fixed effects, the power to find significant differences is limited because few papers study multiple QE programs. Recall from Table 1 that the average (median) article in our sample studies the effects of QE in 1.259 (1) countries.

As noted earlier, our sample contains papers studying not only QE but also other unconventional monetary policy programs, such as long-term refinancing operations. When we exclude those other programs from the analysis, keeping only QE narrowly defined, we find results similar to those in Tables 4 through 6 . We also find similar effects when we control for the time gap between the QE program studied and the year of the paper's first release. This alleviates concerns that the reported differences could be driven by differences in the timing of studies by academics and central bankers. Finally, we look up whether central bank authors work at a research department or a policy department of their central bank at the time of their paper's first public distribution. In unreported results, we find no systematic differences between the results of the two groups of authors.

\subsection{Tone}

We also compare the tone of the language that central bankers and academics use when they summarize their assessments of QE. We focus on the most visible part of the paper: its abstract. We measure the abstract's sentiment score, which equals the share of positive adjectives minus the share of negative adjectives. Our dictionary of positive and negative adjectives is in Table A.1. We estimate the following equation:

$$
y_{i}=\delta_{i}^{U S}+\delta_{i}^{U K}+\delta_{i}^{E A}+\beta[\mathrm{CB} \text { Affiliation }]_{i}+\gamma^{\prime} X_{i}+\epsilon_{i}
$$

where $y_{i}$ is the sentiment score for the abstract of study $i ; \delta_{i}^{U S}, \delta_{i}^{U K}$, and $\delta_{i}^{E A}$ are indicators equal to one if the study analyzes QE in the U.S., UK, or EA, respectively, and zero otherwise; and $X_{i}$ are the same controls as in equation (1). If a paper studies QE in multiple countries, then multiple indicators are switched on.

Panel A of Table 7 shows that central bankers use more positive language than academics when describing their results. Column (3) shows that a 100 percentage point increase in the share of central bank authors is associated with an increase in the sentiment score of 0.056 , which is equivalent to $85 \%$ of one standard deviation of the sentiment score. The result is significant at the $5 \%$ level. In Panels $\mathrm{B}$ and $\mathrm{C}$, we decompose the sentiment score into the shares of positive and negative adjectives, and we run the analysis separately for both shares. We find that central bank studies use both more positive adjectives and fewer negative 
adjectives. The finding based on positive adjectives is economically larger and, unlike the one based on negative adjectives, it is statistically significant.

The evidence that central bankers use more favorable language is not surprising given our results in Sections 3.1 through 3.3. Nonetheless, we find it reassuring that our main result is robust to using a different type of measurement, one based on text rather than numbers. Interestingly, the point estimates of $\beta$ in equation (2) remain very similar when we add controls for the magnitudes of the reported effects on output and inflation. Central bankers thus use more favorable language than academics even when describing point estimates that are equally large. However, the statistical significance of this result is weaker compared to Table 7. Recall that the $\beta$ estimate in column (3) of Panel A of Table 7 is easily significant at the $5 \%$ level. The same estimate remains significant at the $5 \%$ level when we add controls for output effects, standardized or not, but the $p$-value rises to about 0.1 when we control for inflation effects. See the Internet Appendix for details.

We also conduct a textual analysis of the papers' conclusions. The results are qualitatively similar to those based on the abstract - the point estimates of $\beta$ are positive when the left-hand side variable is either the sentiment score or the fraction of positive adjectives, and they are negative for the fraction of negative adjectives - but these results are not statistically significant, as we show in the Internet Appendix. Compared to the abstract, the conclusions usually contain more discussion unrelated to the paper's core contribution, such as comparisons to prior literature and directions for future work.

The Internet Appendix also reports results from the analysis that computes the abstract's sentiment score based on two alternative dictionaries of positive and negative words: the Harvard IV4 semantic dictionary and the Loughran and McDonald (2011) financial dictionary. We do not find significant differences between central bankers and academics based on these alternative dictionaries. However, we find the results based on our simple dictionary far more credible because we designed it specifically for economic research (see Table A.1). In contrast, the Harvard IV4 dictionary is designed for use in a variety of contexts outside economics, and the Loughran-McDonald dictionary is designed for the analysis of 10-K reports of publiclytraded companies. The positive and negative labels assigned to words in these dictionaries do not reflect the meaning of these words in the domain of the economics literature. As a result, these dictionaries do not contain key adjectives that clearly indicate positive language in our context, such as "significant," "large," and "considerable." Moreover, they do contain many words that are irrelevant and potentially even misleading in our context. For example, the words classified as negative in the Loughran and McDonald (2011) lexicon under "A" include "abnormal," "absence," "against," "aftermath," "antitrust," "anomaly," and even "argue" and "argument," thereby casting the whole economic literature in a rather negative 
light (incorrectly, we like to believe).

\section{Mechanism: Management Influence}

This section explores potential reasons for why central bankers are more optimistic than academics in their assessments of QE. Motivated by anecdotal evidence and the arguments in the introduction, we posit that managerial influence at central banks could play a role. In principle, bank management could make promotion decisions in a way that encourages bank employees to report favourable assessments of the bank's policies. We examine this hypothesis in Section 4.1. Bank management can also directly influence research outcomes at various stages of the research production process, from the assignment of the research topic, through the internal review process, to the approval for public distribution. We provide evidence of this influence in Section 4.2. Finally, in Section 4.3, we compare Bundesbank researchers with the rest and examine researchers' methodological choices. None of our evidence proves that bank management causes the results presented in Section 3, but causality seems inherently difficult to establish for such a thorny question. Our conclusion from this section is more modest. Taken together, our results represent the strongest evidence to date of a link between managerial influence and central bank research outcomes.

\subsection{Career Concerns}

To examine the potential for career concerns influencing central bank research, we relate the research findings of central bankers to the bankers' subsequent career outcomes. After manually collecting employment histories for the central bank authors in our sample, we convert their job titles to numerical ranks. We create these ranks on a six-point scale for central bankers, and a four-point scale for academics, by using the dictionary presented in Table A.3. We restrict the analysis to authors who remain affiliated with a central bank and experience at least one career update within five years following the article's first public distribution. We impose the first filter because it is unclear whether transitions to academia or other institutions should be treated as promotions or demotions, and whether they are voluntary or involuntary. The purpose of the second filter is to reduce the noise induced by stale CV information, since authors may not regularly update their job titles. ${ }^{11}$ These filters result in a sample of 33 central bankers (27 of whom are unique) and 23 research papers. We

\footnotetext{
${ }^{11}$ In the Internet Appendix, we report results obtained when we include authors with no career updates, and when we treat departures to academia and the private sector as demotions. Treating departures as demotions leads to similar conclusions. Including authors with no career update within five years of the article's distribution leads to insignificant results, perhaps because of the inclusion of stale information.
} 
then compute a new variable, career outcome, defined as the difference between the author's rank after her first career update following the article's first distribution, and her rank at the time of the article's first distribution. Out of these 33 authors, 19 experience a promotion, 4 experience a demotion, and 10 do not experience any change in rank. ${ }^{12}$

Figure 8 plots the histograms of the estimated effects on output separately for two groups of authors: those who subsequently experience a promotion, that is an increase in rank, and those who subsequently experience either a demotion or no change in rank. We see that for authors who are promoted, the distributions of output effects are clearly shifted to the right compared to the remaining authors. These plots suggest that central bank researchers who report larger effects of QE on output are more likely to get promoted.

In Table 8, we test whether this result is statistically significant and robust to the inclusion of country fixed effects and controls. We regress the author's subsequent career outcome on the estimated effect on output, country fixed effects, and controls:

$$
y_{a i j}=\alpha_{j}+\beta \text { Effect }_{i j}+\gamma^{\prime} X_{a i}+\epsilon_{a i j}
$$

where $y_{a i j}$ is the difference between author $a$ 's rank after her first career update following the first release of study $i$ examining QE in country $j$, and her rank at the time of first release. Note that $y_{a i j}$ does not vary across $j$ for given values of $a$ and $i$. In addition, Effect $_{i j}$ is the effect of QE on output estimated by study $i$ for country $j$ 's QE, $\alpha_{j}$ is a fixed effect for the country in which QE takes place, and $X_{a i}$ are controls. The controls include author experience and the number of authors, as before. In addition, we control for the number of years since the author's most recent career update and for dummy variables indicating the author's rank at the time of the paper's first release, because these variables are important determinants of subsequent career outcomes. The dummy variables are six indicators $\delta_{a i}^{r}$, where $\delta_{a i}^{r}=1$ if author $a$ has rank $r$ at the time of paper $i$ 's first release, and $\delta_{a i}^{r}=0$ otherwise, for $r \in\{1,2, \ldots, 6\}$. Compared to including just one control for the author's rank, including these six controls allows for non-linearities in the relationship between author rank and promotion outcomes.

In Panel A, we find that reporting larger peak and cumulative effects on output is associated with more favorable career outcomes. The point estimate in column (3) implies that a one standard deviation increase in the peak effect improves subsequent career outcomes by 0.59 ranks $(=0.485 \times 1.21)$. In column $(6)$, a one standard deviation increase in the

\footnotetext{
${ }^{12}$ We do not analyze the career outcomes of academics, for two reasons. First, it is unclear a priori why these outcomes should be related to the strength of the academic's findings about QE. Second, the sample size is even smaller than for central bankers. We have only 13 academic authors who remain in academia and experience at least one career update within five years following their article's first public distribution. Among these 13 academics, six experience a promotion and seven have no career change.
} 
cumulative effect on output corresponds to a subsequent rank improvement of 0.57 ranks $(=0.460 \times 1.23)$. Both estimates are significant at the $5 \%$ level. As a reference point, a one-unit change in rank is equivalent to moving, for example, from Economist to Senior Economist, or from Deputy Director to Director.

Panel B of Table 8 shows that the positive relation between career outcomes and estimated effects on output holds also for standardized effects, with statistical significance at the $5 \%$ level in column (6) and 10\% level in column (3). Economically, the effect continues to be large: a one standard deviation increase in the standardized peak effect on output corresponds to an increase in author rank of 0.75 units $(=2.661 \times 0.28)$.

Of course, our finding of a positive association does not establish a causal link between research outcomes and subsequent career outcomes. The outcomes could be correlated for other reasons. For example, studies reporting larger output effects could be easier to publish. Publications, in turn, could lead to promotions. To address this concern, we control for an indicator equal to one if the article came out in a peer-reviewed journal and zero otherwise. The results are similar to those in Table 8 (see the Internet Appendix). For another example, employees who care so much about their employer that they are willing to distort their research findings could show their affection also in other ways, such as by working hard, and those other ways could bring about their promotion. This channel seems harder to control for. Whether central bank research is biased by conflicts of interest is an important but messy question for which clean identification seems inherently difficult to come by.

Among the outcome variables analyzed in Section 3, career outcomes are most closely related to estimated effects on output. For economic significance of output, we find an economically strong relation once all control variables are included, but the relation is not statistically significant. We do not relate career concerns to statistical significance of estimated effects because there is no variation in the subset of central bank papers (recall that they all find statistical significance). There is no significant relation between career outcomes and estimated effects on inflation, as we show in the Internet Appendix.

\subsubsection{Seniority}

Are career concerns stronger for senior or junior central bankers? It is not obvious ex ante for which group of researchers we should expect to see a stronger relation between research findings and subsequent career outcomes. On the one hand, research output may be a more important criterion in the promotions of junior researchers, who spend more time on research and less time on managerial tasks. On the other hand, support from top management may matter more for the career advancement of senior researchers. There may also be more discretion in the promotion decisions at the senior level. 
We address this question in Table 9. We repeat the analysis from Table 8, but now interact Effect ${ }_{i j}$ from equation (3) with the author's career rank (Seniority). To simplify the interpretation of the results, we standardize Seniority to have zero mean and a standard deviation of one. The interaction between the effect on output and author seniority is positive and statistically significant at the $10 \%$ level or lower for all four output effects reported in Panel A. In terms of magnitude, the point estimates imply that a one standard deviation increase in author seniority increases the sensitivity of career outcomes to the estimated effect on output by $45 \%(=0.364 / 0.802)$ to $56 \%(=4.108 / 7.380)$. In Panel B, columns (3) and (4), we find a greater sensitivity of career outcomes to the standardized effect on inflation for more-senior authors. Although the economic magnitude is even larger than for the effect on output, the result is only marginally statistically significant. For the non-standardized effect on inflation (columns (1) and (2)), there is no greater sensitivity for senior authors.

The above results are consistent with career concerns being stronger for senior central bank researchers. If that is the case, and if seniority does not play a similar role for academics (it is not clear why it should), we should expect to see larger differences in research findings between central bankers and academics when the authors on the team are more senior.

We test this prediction in Table 10. We repeat the analysis from Tables 4 through 6 , except that we interact $C B$ Affiliation with the rank of the most senior author on the team, Max Seniority. ${ }^{13}$ We standardize Max Seniority to zero mean and unit standard deviation. For each of the 12 outcome variables, the estimated coefficient on the interaction between $C B$ Affiliation and Max Seniority is positive, implying that central bankers and academics are further apart in their findings if there is a more senior person on the team. The interaction coefficient is statistically significant at the $5 \%$ level for two variables and at the $10 \%$ level for five of the 12 variables. The point estimate in Panel A, column (1), implies that the difference in the estimated peak effect on output between a study with zero central bankers and $100 \%$ central bankers is 1.054 percentage points larger if the rank of the most senior author increases by one standard deviation. For the peak effect on inflation, the effect reported in Panel B, column (1), is even larger, 1.140 percentage points. Even when the interaction coefficient is statistically insignificant, its magnitude is large. For example, the estimates in Panel A, column (3), suggest that increasing Max Seniority by one standard deviation increases the difference in the standardized peak effect on output between central bank and academic studies by 0.152 percentage points. Relative to the average difference of 0.105 notches, this implies more than a doubling of the effect.

In Panel $\mathrm{C}$ of Table 10, we turn to significance. For output, the differences in statistical and economic significance between studies with and without central bankers are $71 \%$ (=

\footnotetext{
${ }^{13}$ The results are weaker if we use the average author rank instead of the rank of the most senior author, suggesting that the seniority of the most senior author matters more. See the Internet Appendix.
} 
$0.335 / 0.472)$ and $70 \%(=0.337 / 0.483)$ larger, respectively, if Max Seniority increases by one standard deviation. These effects are significant at the $10 \%$ and $5 \%$ level, respectively. For inflation, the point estimates also indicate large effects, but they are statistically insignificant. In sum, we find some support for the prediction that differences between the findings of central bankers and academics are larger when there are more-senior authors on the team. The promotion results from Table 9 offer a possible explanation: senior central bankers may report larger QE effects because they are more incentivized to do so.

\subsection{Survey of Central Banks}

Independent of the potential promotion channel, bank management can influence research outcomes in a number of ways. For example, management can assign a topic to a researcher, implicitly signaling the topic's importance to the bank. Superiors can suggest methodologies, data sources, and related literature. If they are not convinced by the paper's results, superiors can return the paper with suggestions for improvement, or even block the paper's release. Management influence is often beneficial to the researcher, providing helpful guidance and valuable resources. Besides anecdotal evidence, the economics profession knows little about the extent of management involvement in central bank research.

To fill this gap, we conduct a survey of research practices at the world's leading central banks. We organized the survey in cooperation with the National Bank of Slovakia. ${ }^{14}$ We reached out to 54 heads of research, covering the central banks in all OECD countries and all EU member states, including the ECB, the Federal Reserve Board, and 12 regional Feds. In return for participating, we promised to share aggregated results with the respondents. We assured them that no individual responses would be published, and that only anonymized responses could be pooled and used for research purposes. We sent out the initial invitation on July 3, 2020; a reminder went out ten days later.

The survey contains four main questions, each containing three to six multiple-choice subquestions, for a total of 18 questions. All questions are mandatory to answer. We also asked for the number of research-active economists in full-time equivalents employed by the bank, the bank's name, and an email address to which we can send summary results.

We have received 24 responses, representing a response rate of $44.4 \%$. Based on selfreported estimates by the respective heads of research, these 24 central banks employ a total of over 750 researchers. ${ }^{15}$

Figure 9 presents the aggregated responses to the four main questions. In response to

\footnotetext{
${ }^{14}$ We thank Martin Šuster, the bank's head of research, for his generous help throughout the process.

${ }^{15}$ We originally received 25 responses but one respondent asked to withdraw from the survey after the first public circulation of our paper. The main conclusion from the survey - that management is substantially involved in research production - is unaffected by the exclusion of this respondent.
} 
the first question, "How are research topics selected in your central bank?", 20 (15) central banks indicate that research topics are at least sometimes (often) mutually agreed by researchers and management, and 17 banks respond that topics are at least sometimes assigned by management. Responding to the second question, "How are draft research papers reviewed/commented on in your institution, prior to their public distribution?", 21 (14) central banks indicate that papers are reviewed at least sometimes (often) by management. In 9 banks, this review happens for all papers. The third question is, "How are your institution's draft research papers approved for public distribution?". Bank management and, most commonly, the head of research, is frequently involved in approving papers for publication: 20 (18) banks respond that the head of research approves papers at least sometimes (often). The bank board also gets involved in the approval process, at least sometimes, in eight banks. Finally, when asked "What criteria can lead to the paper being rejected (i.e., not approved for public distribution)?", most central banks list "substandard methodology, unreliable data, deficient modeling approach", followed by "results not robust or not significant". The latter criteria are used by 18 (10) banks at least sometimes (often).

The results of the survey reveal substantial involvement by management in the research process at most central banks. This involvement creates an opportunity for bank management to influence research outcomes, suggesting that our findings in Section 3 could potentially be driven by managerial influence at central banks.

This interpretation of the survey evidence is subject to numerous caveats. First and foremost, the fact that management involvement exists does not imply that it affects research outcomes as measured in our study. Management involvement is necessary but not sufficient for research outcomes to be influenced by management; the survey evidence thus supports only the necessary condition. The involvement can take different forms, many of which help improve the quality of research output without introducing any bias. For example, many research directors view their role largely as helping their staff write better papers. The first two survey questions pool research directors and senior managers into a single "management" category, masking the different roles of these two types of managers, as well as their potentially different sensitivities to "undesirable" policy messages.

Second, given the survey's brevity, the responses cannot reveal the full range of practices across banks. For example, economists in many banks split their time between policy work and their own research. Management is likely to be more involved in the selection of topics for policy work than for individual research, yet the first survey question does not distinguish between the two types of work. Of course, whether a study of the effectiveness of QE counts as research or policy work may also differ across banks.

Finally, the set of central banks in our survey sample differs from the set of banks whose 
economists are in our pool of authors. While the two sets overlap, the overlap is relatively small because most banks do not employ staff who have written about the effectiveness of QE in the U.S., UK, or EA. We do not know how similar the research processes in the two sets of banks are. If they are substantially different, then our survey sheds little light on the involvement of bank management in the production of studies on QE.

\subsection{Additional Evidence}

Besides analyzing career outcomes and survey responses, we explore several other topics to offer additional evidence on the mechanism behind our main results: the research outcomes of the employees of the German Bundesbank (Section 4.3.1), researchers' methodological choices (Section 4.3.2), and the quality of research output (Section 4.3.3).

\subsubsection{The Bundesbank}

If central bankers' findings regarding QE are colored by the views of bank management, we should see weaker QE effects reported by researchers at central banks whose management has taken a critical stance towards QE. A prominent example is the German Bundesbank, whose top management has publicly criticized the ECB for its bond-buying program. For example, former Bundesbank president Axel Weber and vice president Jürgen Stark resigned from their positions at the ECB, allegedly in protest over QE (Reuters (2011)). The current Bundesbank president as of 2020, Jens Weidmann, has also publicly opposed QE (e.g., Der Spiegel (2012)). It seems plausible to conjecture that these views of the bank's top brass could be reflected in the writings of the bank's researchers.

We test this hypothesis by repeating the analysis in Tables 4 through 6 , replacing $C B$ Affiliation in regression (1) with three indicators: German $C B$ is equal to one if at least one of the authors is employed by the Bundesbank, Other $E A C B$ is equal to one if at least one author works at the ECB or a euro area national central bank other than the Bundesbank, and Non-EA CB is equal to one if at least one author is from a central bank outside the euro area or from the BIS. The omitted group are academics. If a paper has authors from both the Bundesbank and the ECB or another euro area national central bank, then both the German $C B$ indicator and the Other EA CB indicator are equal to one.

Panel A of Table 11 shows that Bundesbank authors find strikingly different results regarding the effectiveness of QE in raising output. Bundesbank papers report smaller effects of QE on output compared to academics, on average, whereas other central banks, both inside and outside the euro area, find larger effects. This pattern holds for all four measures of output. For example, the estimates in column (1) imply that the average estimated peak effect on output for Bundesbank papers is 0.884 percentage points smaller than the average 
peak effect for academics. In contrast, other central banks in the euro area find effects that are 0.444 percentage points larger, and banks outside the euro area find effects that are 0.688 percentage points larger, on average, compared to academics. The difference in the point estimates for German $C B$ and Other EA CB, unreported for brevity, is mostly statistically significant based on cluster-robust standard errors but not based on bootstrapped $p$-values, in part because there are only four Bundesbank papers in our sample. The small-sample problem is inherent to this exercise because of the relatively short period over which papers on QE could be written since the first QE program in our sample was conducted. Nevertheless, the different signs and large magnitudes of the coefficients reinforce the managerial influence interpretation of our main results.

For the effect on inflation, reported in Panel B, the differences between Bundesbank authors and other central bankers are much smaller. Moreover, unlike in Panel A, the Bundesbank estimates of the QE effects exceed those of academics. The weaker results for inflation make sense. German opposition to ECB's QE has been based largely on concerns about redistribution within the euro area, not on concerns about QE being ineffective at raising inflation. On the contrary, a popular view in Germany is that QE could well be too effective in that regard. The view that printing money causes inflation is traditionally strong in Germany, whose collective memory is still scarred by the hyperinflation that took place in the Weimar Republic in the early 1920s.

\subsubsection{Methodological Choices}

Researchers analyzing the same phenomenon by using different methodologies can arrive at different conclusions. We examine two methodological choices that authors make: which model to use and how, if at all, to report statistical significance. We find differences between central bankers and academics in both dimensions. These differences offer possible clues as to why these groups report different results regarding the effectiveness of QE.

First, we test whether central bankers and academics are equally likely to disclose the width of the confidence interval (or, alternatively, the standard error) used to assess statistical significance. We estimate a linear probability model that regresses an indicator equal to one if the paper does not disclose the confidence interval, and zero if it does, on the share of central-bank-affiliated authors. This matches the regression specification in equation (2), with $y_{i}$ denoting an indicator for nondisclosure. We restrict the sample to studies that comment on the statistical significance of either output or inflation.

Panel A of Table 12 shows that central bankers are more likely to not disclose the width of the confidence interval. Column (3), which reports results from the specification that includes

country fixed effects and controls, shows that papers with 100\% central bank authors are 
44.9 percentage points more likely to not report the width of the confidence interval than papers with no central bank authors. That is a very significant effect, both statistically and economically. When the confidence interval is not disclosed, it is more difficult to corroborate the author's verbal assessment of statistical significance.

We also ask which studies assess significance by using unusually narrow confidence intervals - ones constructed at the $68 \%$ confidence level, rather than the more typical $90 \%$ or $95 \%$. A study using a $68 \%$ confidence interval is more likely to find significance because it effectively uses one standard deviation confidence bands instead of the more typical twostandard-deviation bands. We redefine $y_{i j}$ in equation (1) to be an indicator equal to one if the study either uses a $68 \%$ confidence interval or does not disclose this interval at all, and zero otherwise. The results are in Panel A of Table 12, columns (4) through (6). Column (6), which imposes the strictest controls, shows that papers with $100 \%$ central bank authors are 27.6 percentage points more likely to use a narrow or non-specified confidence interval than papers with no central bank authors. The result is significant at the $5 \%$ level. ${ }^{16}$

Second, we explore differences in model choice. The most commonly used models in our sample, by far, are DSGE and VAR models. We redefine $y_{i j}$ to be an indicator equal to one if the study uses a DSGE model, and zero otherwise. We then regress $y_{i j}$ on the share of central bank authors, again using a linear probability model following equation (1). Panel B of Table 12 shows that central bankers are more likely to use DSGE models. Column (3) shows that papers with $100 \%$ central bank authors are 31.9 percentage points more likely to use a DSGE model than papers with no central bank authors. Although this difference is large economically, it is only marginally statistically significant.

One weakness of DSGE models is the fragility of their parameter estimates across empirical studies (e.g., Schorfheide (2013)). This fragility results in part from different structural choices made by different users of these models. A user aiming for a particular outcome can pull on a number of levers to get closer to that outcome. If DSGE models lead to a greater dispersion in estimates across studies compared to VAR models, then the former models could be the more natural choice for an author with a particular outcome in mind. However, testing this hypothesis is difficult because we cannot observe the distribution of all hypothetical research outcomes for each type of model. In the Internet Appendix, we report the standard deviation of the realized research outcomes for the two types of models, and find mixed results. While the dispersion in estimates is higher among DSGE models for the effect on output, it is smaller for the effect on inflation.

\footnotetext{
${ }^{16}$ The choice of a narrow confidence interval could, in principle, be related to the type of statistical inference used (Bayesian versus frequentist). However, we find very similar results when we control for a dummy variable indicating the Bayesian/frequentist approach. See the Internet Appendix.
} 


\subsubsection{Alternative Mechanisms}

Besides managerial influence, other mechanisms could potentially contribute to the observed differences between the findings of central bankers and academics. One such mechanism is differences in priors. Researchers with different priors about the power of policy interventions may self-select into different institutions. For example, if researchers optimistic about QE self-select into central banks, or the pessimists select into academia, then this selection could explain the differences in research outcomes between central bankers and academics. Moreover, differences in priors can be subsequently reinforced during the research process, both by the researcher herself (confirmation bias) and by the feedback she receives from her like-minded peers inside her institution and her social networks.

Another potential mechanism is reputation concerns. These could involve concerns about the bank's reputation and, if the researcher is senior enough to have participated in the formation of the policy, concerns about her own reputation. Unfortunately, disentangling these alternative explanations from managerial influence is inherently difficult, as they share multiple empirical predictions. While we cannot rule out these mechanisms, two other explanations seem unlikely, as we explain next.

One possibility is that papers on QE written by central bankers and academics are of different quality. For example, if central bank papers were of higher quality and the effects of QE were truly strong, then we would expect central bank papers to find stronger QE effects. Given the management involvement documented earlier, it is indeed possible that central banks have a more rigorous vetting process for new working papers compared to universities, allowing central banks to discard lower-quality papers. Moreover, central bankers may simply know more about QE than academics, given the nature of the subject.

However, higher research quality at central banks seems unlikely to explain our results, for three reasons. First, if central bank papers are of higher quality, they should be more likely to report confidence intervals, and presumably also to use a higher threshold for statistical significance. Instead, we find the opposite in Table 12. Second, papers written by central bankers and academics are of comparable quality, based on three measures of quality: publication status, journal impact factor, and the article influence score. We show this in the Internet Appendix. ${ }^{17}$ Finally, to explain the opposite results regarding output for Bundesbank authors, a story based on differential research quality would have to assume that Bundesbank research is of different quality compared to other central banks.

Another possible explanation for our results, communicated to us by a central banker, is

\footnotetext{
${ }^{17}$ In the same Appendix, we also show that the difference in research findings between central bankers and academics remains largely unchanged once we condition on published papers only, as well as once we condition on papers published in journals whose impact factor is at least 1.0.
} 
that academics have an incentive to seek sensational results - such as that vast amounts of spending by central banks were ineffective in improving macroeconomic outcomes - to boost their reputations. Two facts cast doubt on this explanation. First, academic reputation is generally judged by the publication record. Finding a null result makes a paper substantially harder, not easier, to publish (recall the publication bias discussed earlier). Consistent with this view, we show in the Internet Appendix that finding larger effects of QE on output increases the odds of publication in a peer-reviewed journal. Second, if the results were driven by academics' career concerns, then we should see stronger results among junior authors, who strive to earn tenure, than among senior authors. In contrast, recall from Table 10 that differences between the findings of central bankers and academics are more pronounced among senior researchers.

\section{Conclusion}

We analyze the conflict of interest faced by central bank economists who conduct research evaluating central bank policies. Comparing the findings of central bankers and academics regarding the effectiveness of $\mathrm{QE}$, we find that central bank studies report stronger effects of QE on both output and inflation. Central bank studies are also more likely to report QE effects on output that are significant, and their abstracts use more favorable language. Overall, central bankers find QE to be more effective compared to academics.

Of course, this evidence does not imply that central bank research is biased. Perhaps academic research is biased toward insignificance. However, given the publication bias in academic journals, academics have their own incentive to find significant effects. Moreover, additional evidence suggests a role for career concerns. We find that central bankers whose papers report larger effects of QE on output have better career outcomes. The somewhat weaker effects found by Bundesbank researchers are also consistent with career concerns. Finally, our survey reveals that in most central banks, management influences research topics, reviews papers, and approves them for public distribution. The involvement of bank management in the production of bank research extends far beyond that of university management in academic research. This involvement seems necessary, at least to some extent, given the broader mission of a central bank. The extent to which this involvement affects research outcomes remains unclear, creating opportunities for future research.

Importantly, we do not argue that central bank research should be discounted. In many ways, central banks are in an excellent position to provide accurate assessments of their own policies. Like pharmaceutical firms studying their own drugs, central banks have superior information about their own products, exceptionally strong expertise in the subject matter, 
and an intense desire to preserve their reputation. In addition, central banks are public institutions whose integrity is generally held in very high esteem. They understand that the effectiveness of their policy is predicated on their own credibility. We are not questioning that credibility. We simply highlight a previously unexplored conflict of interest that has the potential to influence a subset of bank research. We hope that our study will help central banks think through the implications of this conflict for their research processes. 


\section{References}

Andersen, Jorgen Juel, Johannesen, Niels and Rijkers, Bob (2020), Elite capture of foreign aid: Evidence from offshore bank accounts, Technical Report WPS 9150, Policy Research working paper, World Bank Group.

Asatryan, Zareh, Havlik, Annika, Heinemann, Friedrich and Nover, Justus (2020), Biases in fiscal multiplier estimates, European Journal of Political Economy 63, 101861.

Bailey, Charles N., Hasselback, James R. and Karcher, Julia N. (2001), Research misconduct in accounting literature: A survey of the most prolific researchers' actions and beliefs, Abacus 37(1), 26-54.

Banerjee, Abhijit V., Deaton, Angus, Lustig, Nora, Rogoff, Kenneth and Hsu, Edward (2006), An evaluation of World Bank research, 1998-2005, Technical report, World Bank, Washington, DC.

Bekelman, Justin E., Li, Yan and Gross, Cary P. (2003), Scope and impact of financial conflicts of interest in biomedical research: A systematic review, Journal of the American Medical Association 289(4), 454-465.

Benson, Alan, Li, Danielle and Shue, Kelly (2019), Promotions and the Peter principle, Quarterly Journal of Economics 134(4), 2085-2134.

Bernanke, Ben S. (2020), The new tools of monetary policy, American Economic Review $110(4), 943-983$.

Besley, Timothy, Meads, Neil and Surico, Paolo (2008), Insiders versus outsiders in monetary policymaking, American Economic Review 98(2), 218-223.

Blanes i Vidal, Jordi, Draca, Mirko and Fons-Rosen, Christian (2012), Revolving door lobbyists, American Economic Review 102(7), 3731-3748.

Bolton, Patrick, Freixas, Xavier and Shapiro, Joel (2012), The credit ratings game, Journal of Finance 67(1), 85-111.

Brodeur, Abel, Lé, Mathias, Sangnier, Marc and Zylberberg, Yanos (2016), Star wars: The empirics strike back, American Economic Journal: Applied Economics 8(1), 1-32.

Cameron, A. Colin, Gelbach, Jonah B. and Miller, Douglas L. (2008), Bootstrap-based improvements for inference with clustered errors, Review of Economics and Statistics $90(3), 414-427$.

Cameron, A. Colin and Miller, Douglas L. (2015), A practitioner's guide to cluster-robust inference, Journal of Human Resources 50(2), 317-372.

Carrick-Hagenbarth, Jessica and Epstein, Gerald A. (2012), Dangerous interconnectedness: Economists' conflicts of interest, ideology and financial crisis, Cambridge Journal of Economics 36(1), 43-63. 
Chevalier, Judith and Ellison, Glenn (1999), Career concerns of mutual fund managers, Quarterly Journal of Economics 114(2), 389-432.

Christensen, Garret and Miguel, Edward (2018), Transparency, reproducibility, and the credibility of economics research, Journal of Economic Literature 56(3), 920-980.

Collier, Joe and Iheanacho, Ike (2002), The pharmaceutical industry as an informant, Lancet 360(9343), 1405-1409.

Cornaggia, Jess, Cornaggia, Kimberly J. and Xia, Han (2016), Revolving doors on Wall Street, Journal of Financial Economics 120(2), 400-419.

Davidson, Russell and MacKinnon, James G. (2010), Wild bootstrap tests for IV regression, Journal of Business \& Economic Statistics 28(1), 128-144.

De Long, J. Bradford and Lang, Kevin (1992), Are all economic hypotheses false?, Journal of Political Economy 100(6), 1257-1272.

Dell'Ariccia, Giovanni, Rabanal, Pau and Sandri, Damiano (2018), Unconventional monetary policies in the Euro Area, Japan, and the United Kingdom, Journal of Economic Perspectives 32(4), 147-172.

Der Spiegel (2012), Too close to state financing via the money press. Interview conducted by Georg Mascolo, Michael Sauga and Anne Seith. Translated from German by Paul Cohen. August 29. URL: https://www.spiegel.de/international/europe/spiegel-interviewwith-bundesbank-president-jens-weidmann-a-852285.html.

Doucouliagos, Chris and Stanley, T. D. (2013), Are all economic facts greatly exaggerated? Theory competition and selectivity, Journal of Economic Surveys 27(2), 316-339.

Fanelli, Daniele (2009), How many scientists fabricate and falsify research? A systematic review and meta-analysis of surveydata, PLOS ONE 4(5), 1-11.

Fanelli, Daniele (2010a), Do pressures to publish increase scientists' bias? An empirical support from US states data, PLOS ONE 5(4), 1-7.

Fanelli, Daniele (2010b), "Positive" results increase down the hierarchy of the sciences, PLOS ONE 5(4), 1-10.

Fanelli, Daniele (2012), Negative results are disappearing from most disciplines and countries, Scientometrics 90(3), 891-904.

Fanelli, Daniele, Costas, Rodrigo and Ioannidis, John P. A. (2017), Meta-assessment of bias in science, Proceedings of the National Academy of Sciences 114(14), 3714-3719.

Franco, Annie, Malhotra, Neil and Simonovits, Gabor (2014), Publication bias in the social sciences: Unlocking the file drawer, Science 345(6203), 1502-1505.

Gentzkow, Matthew and Shapiro, Jesse M. (2010), What drives media slant? Evidence from U.S. daily newspapers, Econometrica 78(1), 35-71. 
Gerlach-Kristen, Petra (2009), Outsiders at the Bank of England's MPC, Journal of Money, Credit and Banking 41(6), 1099-1115.

Griffin, John M. and Tang, Dragon Yongjun (2012), Did subjectivity play a role in CDO credit ratings?, Journal of Finance 67(4), 1293-1328.

Groseclose, Tim and Milyo, Jeffrey (2005), A measure of media bias, Quarterly Journal of Economics 120(4), 1191-1237.

Hansen, Stephen, McMahon, Michael and Prat, Andrea (2018), Transparency and deliberation within the FOMC: A computational linguistics approach, Quarterly Journal of Economics 133(2), 801-870.

Hong, Harrison and Kacperczyk, Marcin (2010), Competition and bias, Quarterly Journal of Economics 125(4), 1683-1725.

Hong, Harrison and Kubik, Jeffrey D. (2003), Analyzing the analysts: Career concerns and biased earnings forecasts, Journal of Finance 58(1), 313-351.

Hong, Harrison, Kubik, Jeffrey D. and Solomon, Amit (2000), Security analysts' career concerns and herding of earnings forecasts, RAND Journal of Economics 31(1), 121-144.

Ioannidis, John P. A. (2005), Why most published research findings are false, PLOS Medicine $2(8)$, e124.

Ioannidis, John P. A. and Doucouliagos, Chris (2013), What's to know about the credibility of empirical economists?, Journal of Economic Surveys 27(5), 997-1004.

Ioannidis, John P. A., Stanley, T. D. and Doucouliagos, Chris (2017), The power of bias in economics research, Economic Journal 127(605), F236-F265.

Jelveh, Zubin, Kogut, Bruce and Naidu, Suresh (2018), Political language in economics, Technical Report 14-57, Research Paper, Columbia Business School.

Jiang, John (Xuefeng), Stanford, Mary Harris and Xie, Yuan (2012), Does it matter who pays for bond ratings? Historical evidence, Journal of Financial Economics 105(3), 607-621.

Kempf, Elisabeth (2020), The job rating game: Revolving doors and analyst incentives, Journal of Financial Economics 135(1), 41-67.

Leamer, Edward E. (1983), Let's take the con out of econometrics, American Economic Review 73(1), 31-43.

Lexchin, Joel, Bero, Lisa A., Djulbegovic, Benjamin and Clark, Otavio (2003), Pharmaceutical industry sponsorship and research outcome and quality: Systematic review, BMJ 326(7400), 1167-1170.

List, John A., Bailey, Charles D., Euzent, Patricia J. and Martin, Thomas L. (2001), Academic economists behaving badly? A survey on three areas of unethical behavior, Economic Inquiry 39(1), 162-170. 
Loughran, Tim and McDonald, Bill (2011), When is a liability not a liability? Textual analysis, dictionaries, and 10-ks, Journal of Finance 66(1), 35-65.

Lucca, David, Seru, Amit and Trebbi, Francesco (2014), The revolving door and worker flows in banking regulation, Journal of Monetary Economics 65, 17-32.

MacKinnon, James G. and Webb, Matthew D. (2017), Wild bootstrap inference for wildly different cluster sizes, Journal of Applied Econometrics 32(2), 233-254.

Malmendier, Ulrike and Shanthikumar, Devin (2007), Are small investors naive about incentives?, Journal of Financial Economics 85(2), 457-489.

Martin, Christopher and Milas, Costas (2012), Quantitative easing: a sceptical survey, $O x$ ford Review of Economic Policy 28(4), 750-764.

Mathis, Jérôme, McAndrews, James and Rochet, Jean-Charles (2009), Rating the raters: Are reputation concerns powerful enough to discipline rating agencies?, Journal of Monetary Economics 56(5), 657-674.

Meade, Ellen E. and Stasavage, David (2008), Publicity of debate and the incentive to dissent: Evidence from the US Federal Reserve, Economic Journal 118(528), 695-717.

Michaely, Roni and Womack, Kent L. (1999), Conflict of interest and the credibility of underwriter analyst recommendations, Review of Financial Studies 12(4), 653-686.

Mullainathan, Sendhil and Shleifer, Andrei (2005), The market for news, American Economic Review 95(4), 1031-1053.

Nickerson, Raymond S. (1998), Confirmation bias: A ubiquitous phenomenon in many guises, Review of General Psychology 2(2), 175-220.

Reuter, Jonathan and Zitzewitz, Eric (2006), Do ads influence editors? Advertising and bias in the financial media, Quarterly Journal of Economics 121(1), 197-227.

Reuters (2011), Top German quits ECB over bond-buying row. Author: Andreas Framke, September 9. URL: https://www.reuters.com/article/us-ecb-stark/top-german-quits-ecbover-bond-buying-row-idUSTRE7883DF20110909.

Roodman, David, Ørregaard Nielsen, Morten, MacKinnon, James G. and Webb, Matthew D. (2019), Fast and wild: Bootstrap inference in Stata using boottest, Stata Journal 19(1), 460.

Sage, William M. (2007), Some principles require principals: Why banning conflicts of interest won’t solve incentive problems in biomedical research, Texas Law Review 85, 1413-1463.

Schorfheide, Frank (2013), Estimation and evaluation of DSGE models: Progress and challenges, in Daron Acemoglu, Manuel Arellano and Eddie Dekel, eds, Advances in economics and econometrics: Tenth world congress, Vol. 3 of Econometric Society Monographs, Cambridge University Press, pp. 184-230. 
Sibert, Anne (2003), Monetary policy committees: Individual and collective reputations, Review of Economic Studies 70(3), 649-665.

Sismondo, Sergio (2008), Pharmaceutical company funding and its consequences: A qualitative systematic review, Contemporary Clinical Trials 29(2), 109-113.

The Economist (2020), The World Bank loses another chief economist. February 13. URL: https://www.economist.com/finance-and-economics/2020/02/13/the-worldbank-loses-another-chief-economist.

The Financial Times (2015), Four reasons why QE will be different in the eurozone. Author: Ferdinando Giugliano, January 20. URL: https://www.ft.com/content/b4b64b969fe1-11e4-9a74-00144feab7de.

Warner, Jerold B., Watts, Ross L. and Wruck, Karen H. (1988), Stock prices and top management changes, Journal of Financial Economics 20, 461-492.

Weale, Martin and Wieladek, Tomasz (2016), What are the macroeconomic effects of asset purchases?, Journal of Monetary Economics 79, 81-93.

Weisbach, Michael S. (1988), Outside directors and CEO turnover, Journal of Financial Economics 20, 431-460.

Zingales, Luigi (2013), Preventing economists' capture, in Daniel Carpenter and David A. Moss, eds, Preventing regulatory capture: Special interest influence and how to limit it, Cambridge University Press, pp. 124-151. 


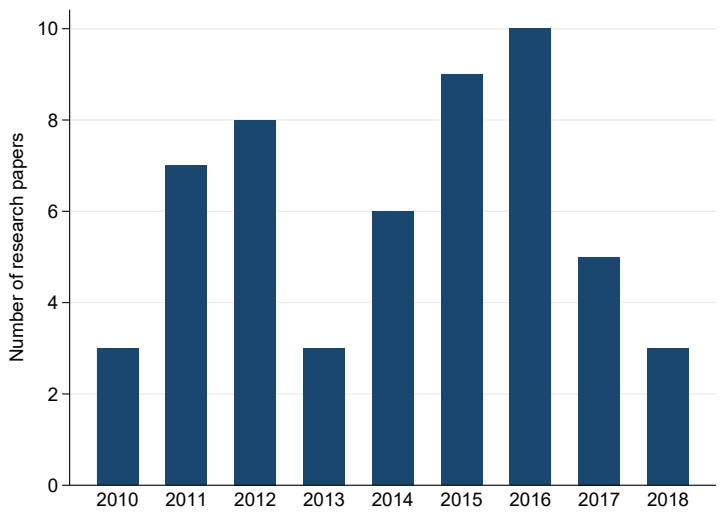

(A) Papers by Year

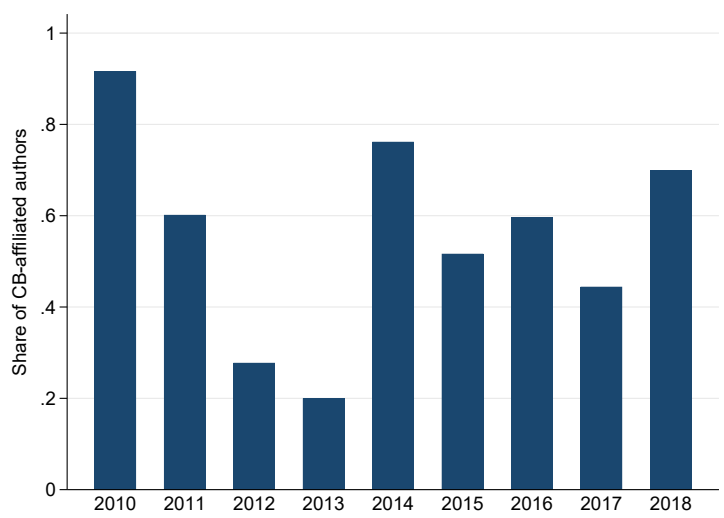

(C) CB Affiliation by Year

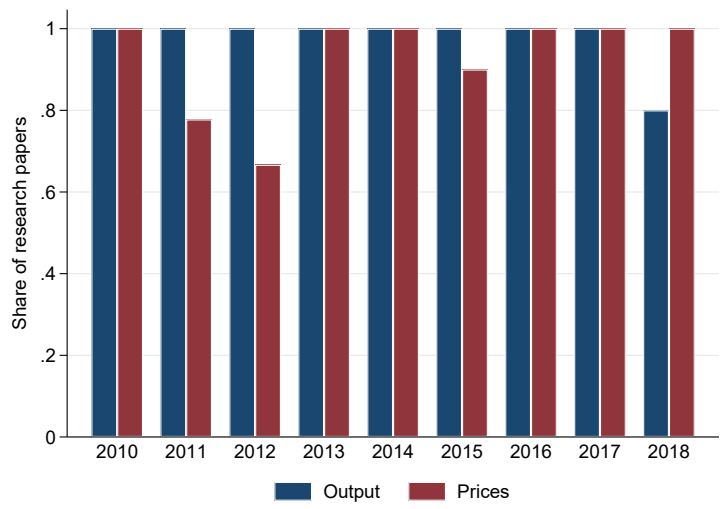

(E) Outcome Variables by Year

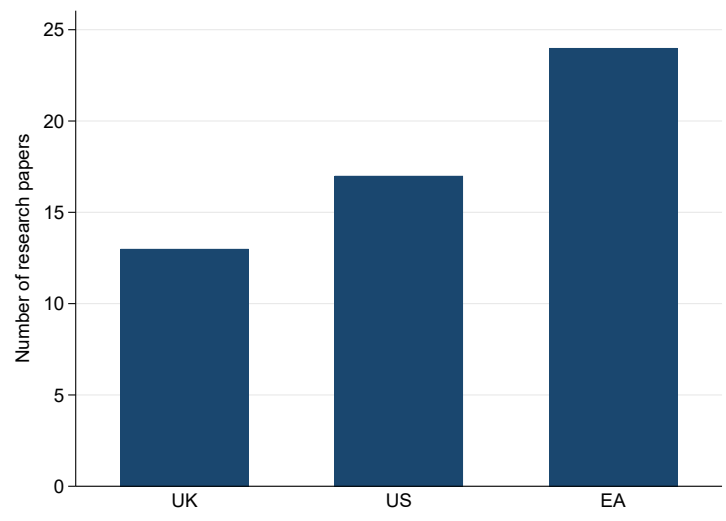

(B) Papers by Country Studied

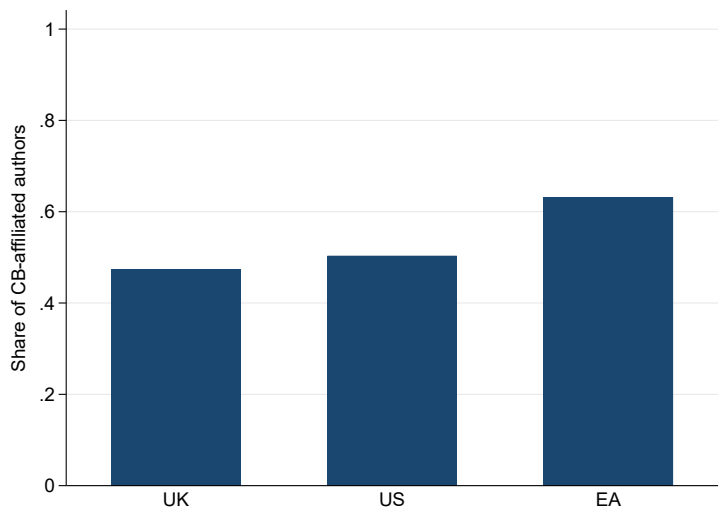

(D) CB Affiliation by Country Studied

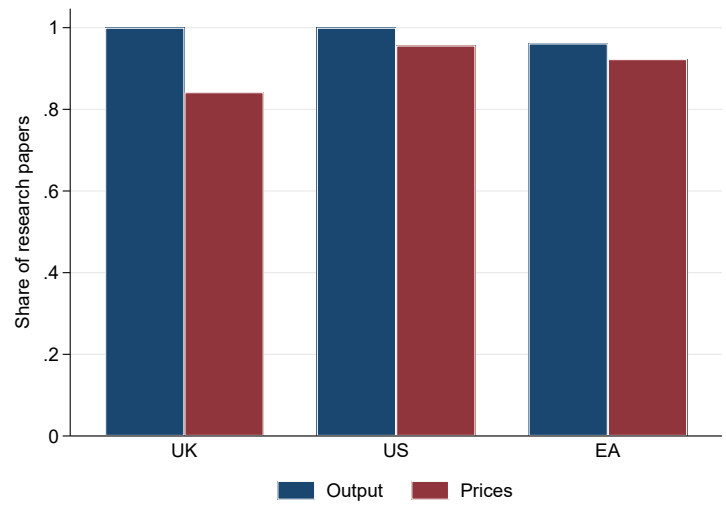

(F) Outcome Variables by Country Studied

Figure 1: Summary Statistics. The figure plots summary statistics at the paper level. Panel A reports the number of research papers by calendar year of first circulation. Panel B reports the number of research papers by country studied. Panels C and D show the average share of central bank (CB)-affiliated authors by calendar year of first circulation and by country studied, respectively. Panels E and F show the average share of papers that study the effect of $\mathrm{QE}$ on output and prices by calendar year of first circulation and by country studied, respectively. 


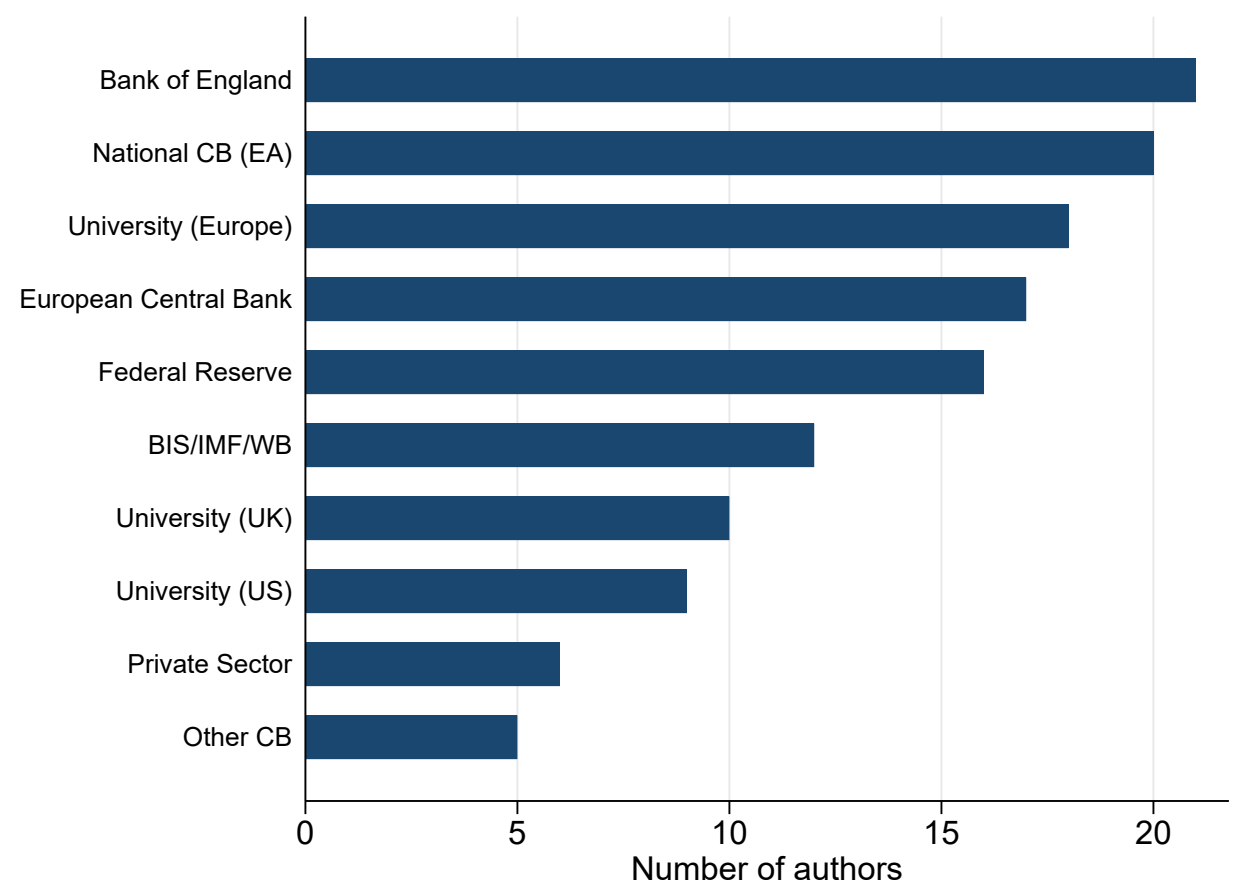

(A) Author Count by Employer

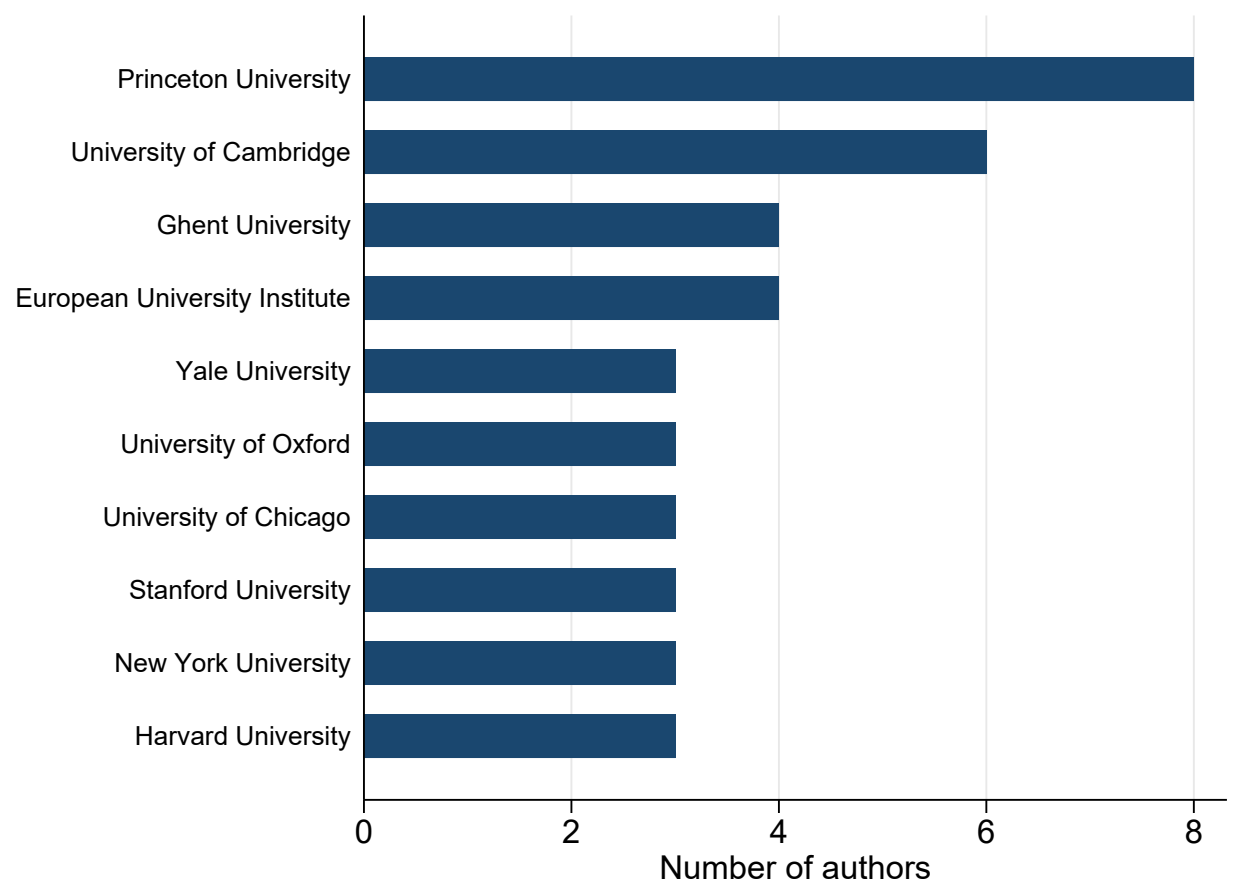

(B) Author Count by PhD Institution

Figure 2: Number of Authors by Employer and PhD Institution. The figure plots the number of authors by employer type (Panel A) and by PhD institution (Panel B). We restrict the graphs to employer types and $\mathrm{PhD}$ institutions with at least three affiliated authors. The unit of observation is at the author-paper level in Panel A, and the author level in Panel B. 


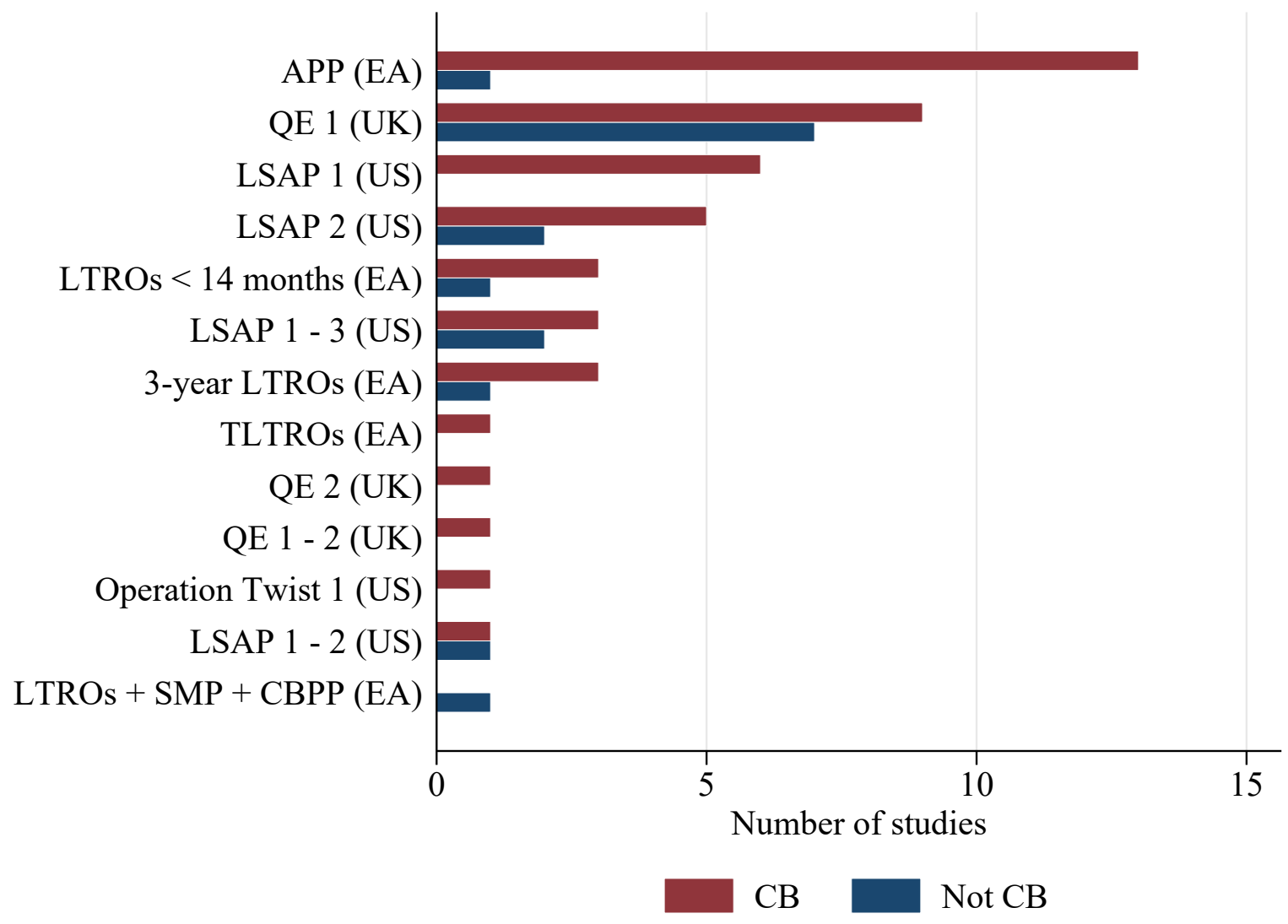

Figure 3: Number of Studies by QE Program. The figure plots the number of studies by QE program studied, separately for papers with and without CB-affiliated authors. Here we pool central bankers and BIS authors. 


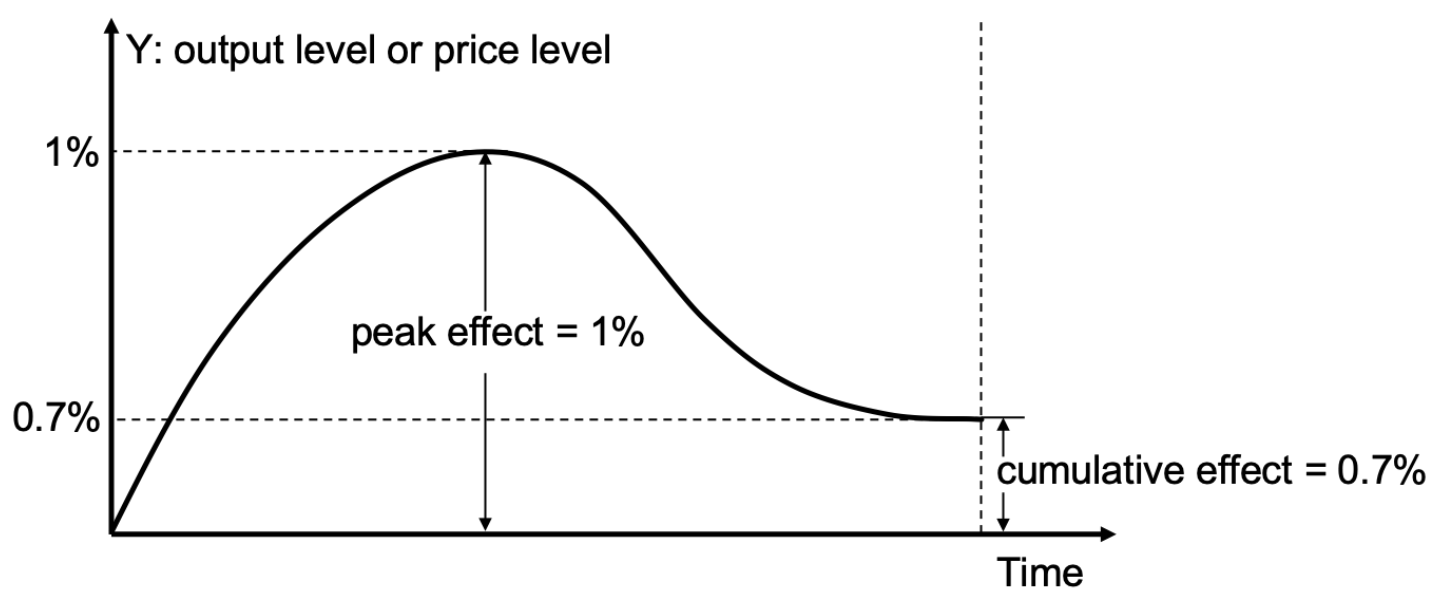

Figure 4: Visualization of the Peak and Cumulative Effects. The figure illustrates how we compute the peak and cumulative effects of QE on the level of the outcome variable for the most common case, in which the authors plot the effect of QE on the level of the outcome variable. 
CB

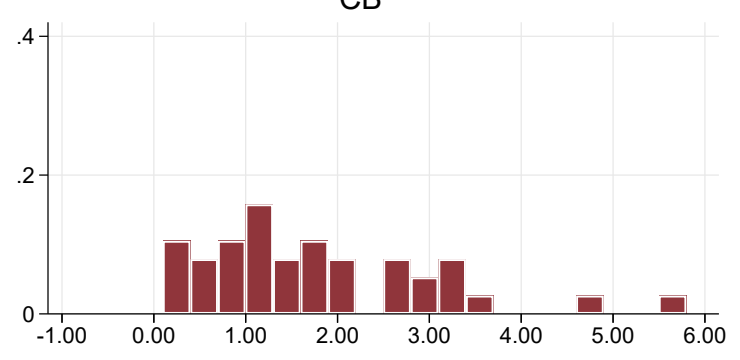

Not CB

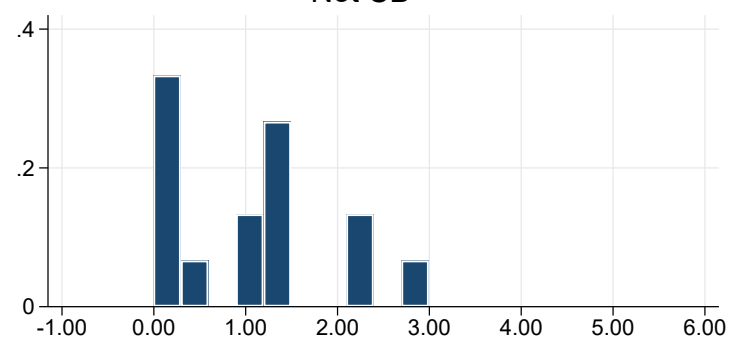

(A) Total Peak Effect

CB

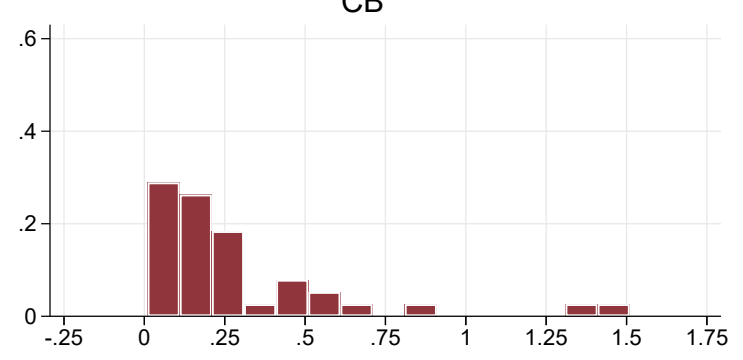

Not CB

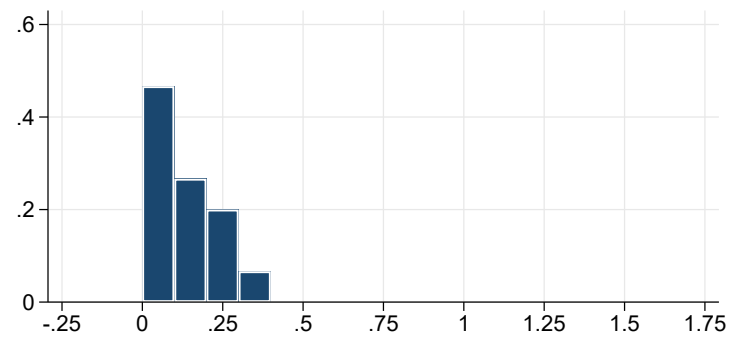

(C) Standardized Peak Effect

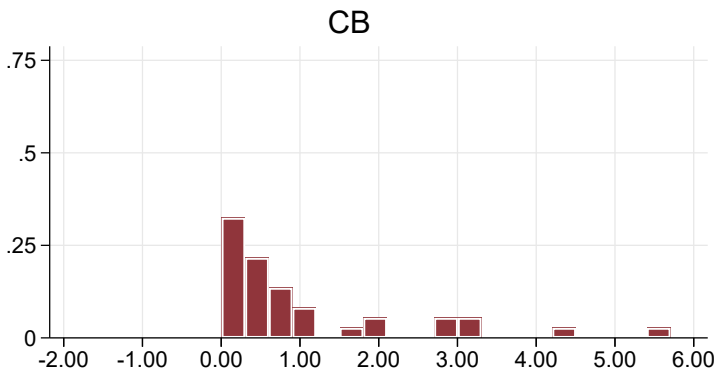

Not CB

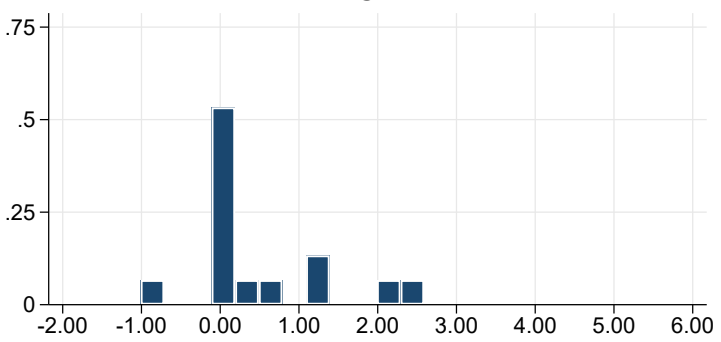

(B) Total Cumulative Effect

CB

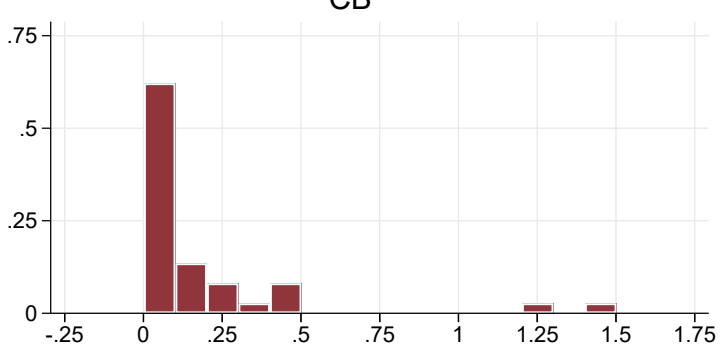

Not CB

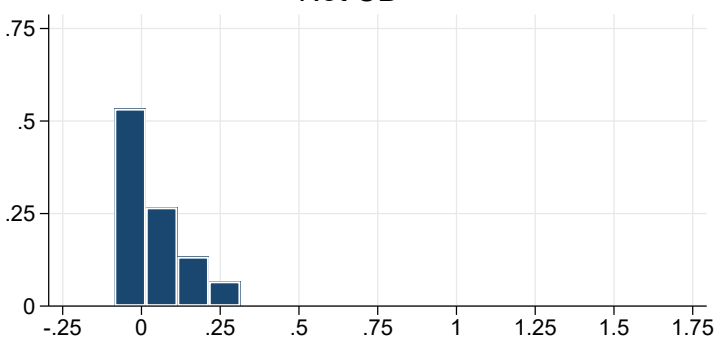

(D) Standardized Cumulative Effect

Figure 5: The Effect on Output by Central Bank Affiliation. The figure plots histograms for the estimated effect on output, separately for papers with and without CBaffiliated authors. Panels $\mathrm{A}$ and $\mathrm{B}$ show the total estimated peak and cumulative effects of the QE program studied on the level of output. Panels C and D show the estimated peak and cumulative effects of the QE program studied on the level of output, after standardizing the QE shock size to $1 \%$ of GDP. 
CB

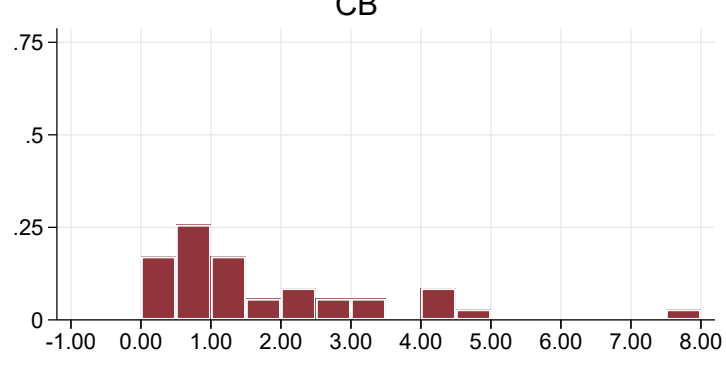

Not CB

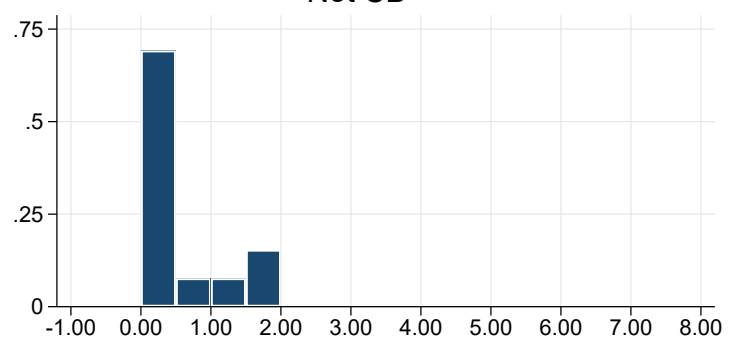

(A) Total Peak Effect

CB

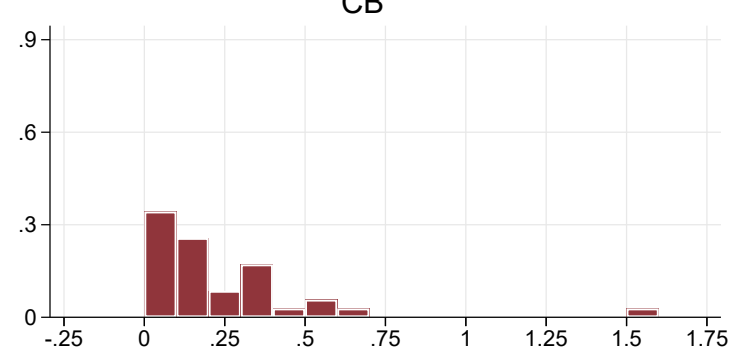

Not CB

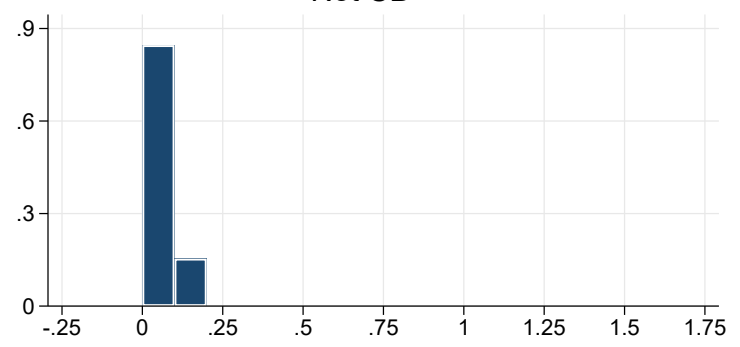

(C) Standardized Peak Effect

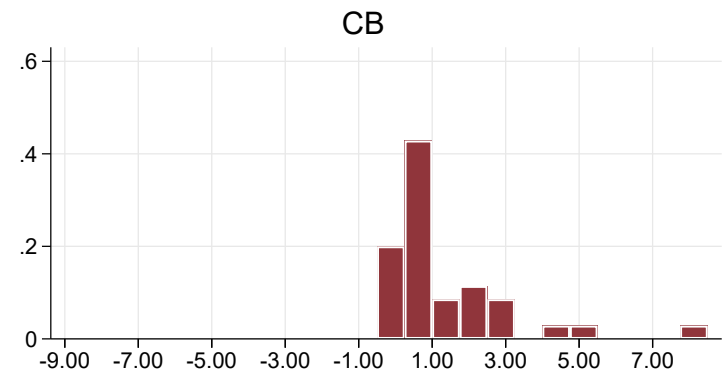

Not CB

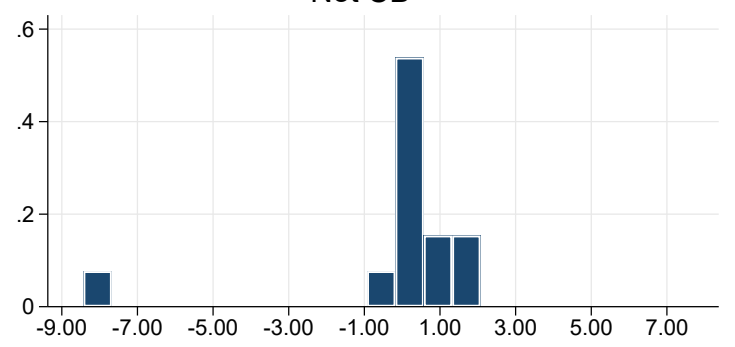

(B) Total Cumulative Effect

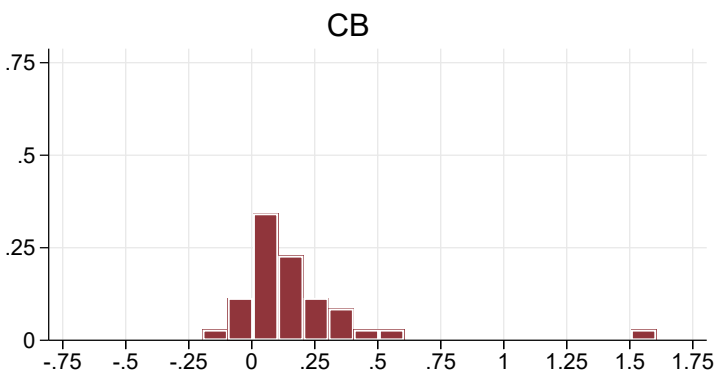

Not CB

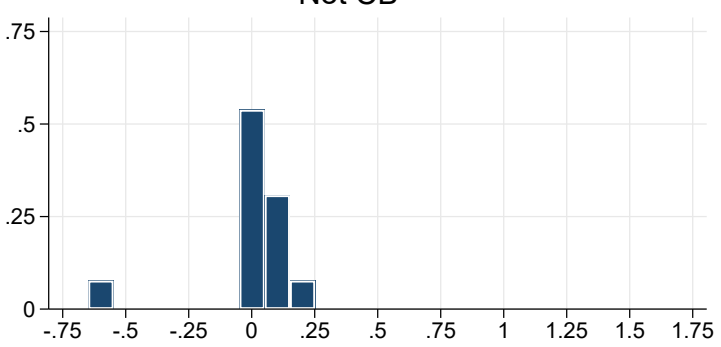

(D) Standardized Cumulative Effect

Figure 6: The Effect on Inflation by Central Bank Affiliation. The figure plots histograms for the estimated effect on inflation, separately for papers with and without CBaffiliated authors. Panels $\mathrm{A}$ and $\mathrm{B}$ show the total estimated peak and cumulative effects of the QE program studied on the price level. Panels C and D show the estimated peak and cumulative effects of the QE program studied on the price level, after standardizing the QE shock size to $1 \%$ of GDP. 
CB

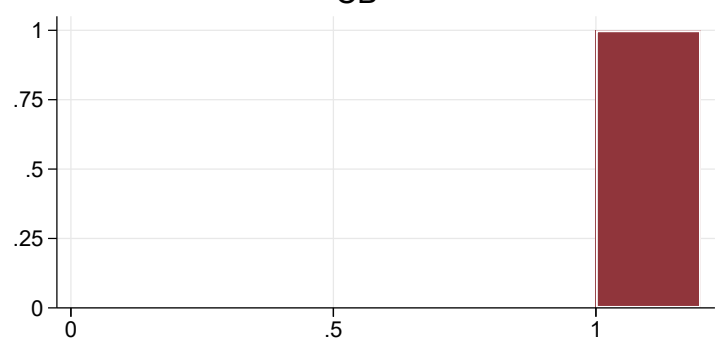

Not CB

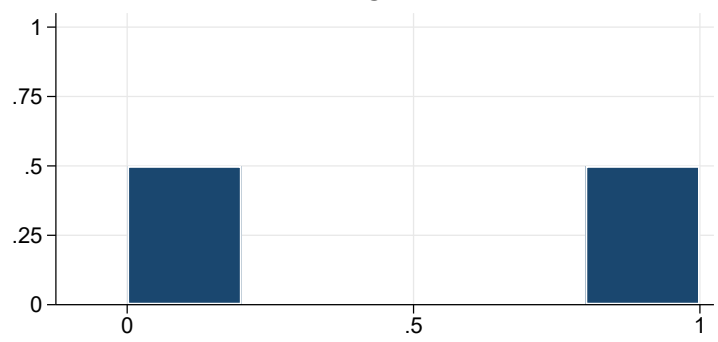

(A) Statistical Significance: Output

$\mathrm{CB}$

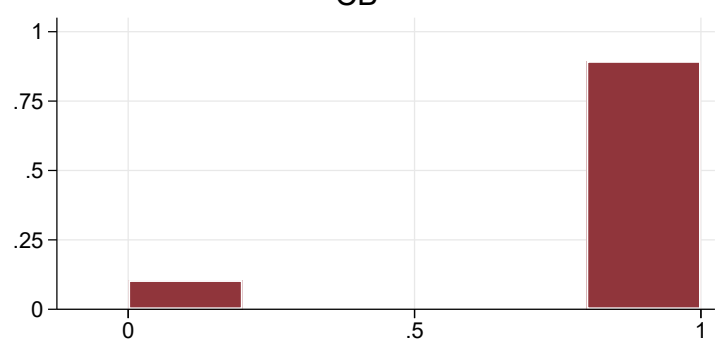

Not CB

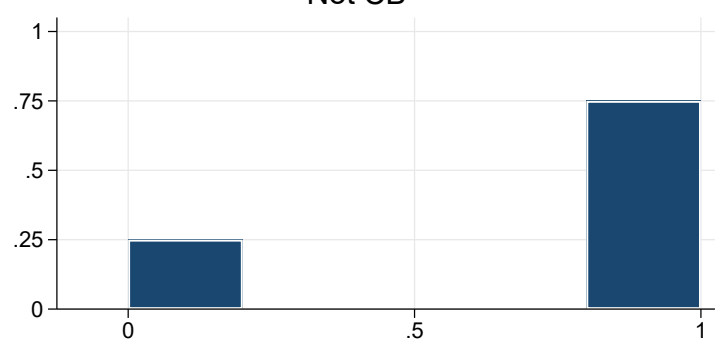

(C) Statistical Significance: Inflation

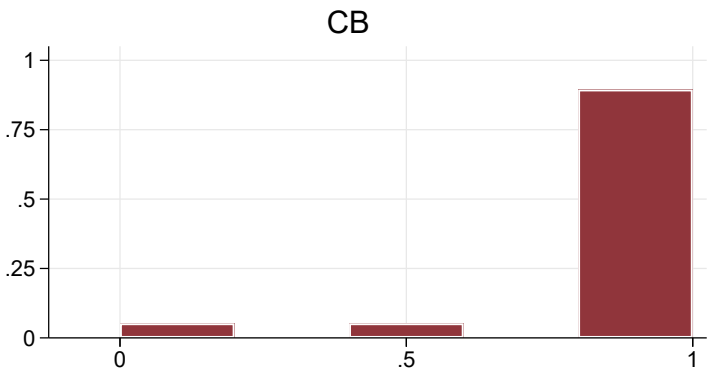

Not $\mathrm{CB}$

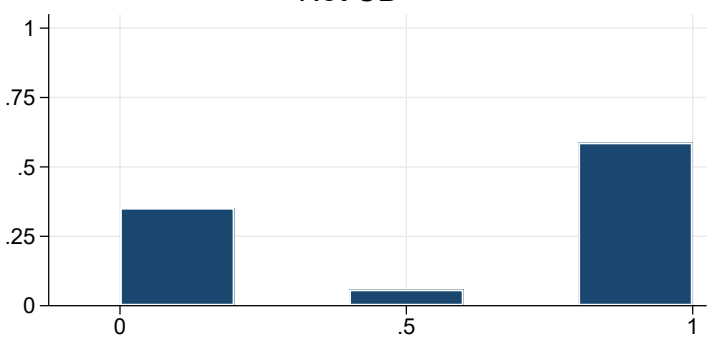

(B) Economic Significance: Output

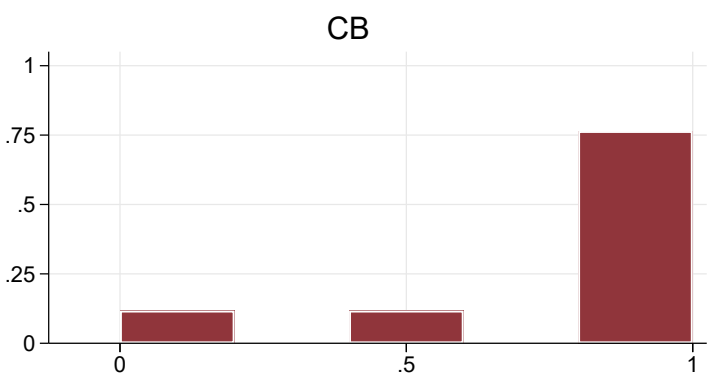

Not CB

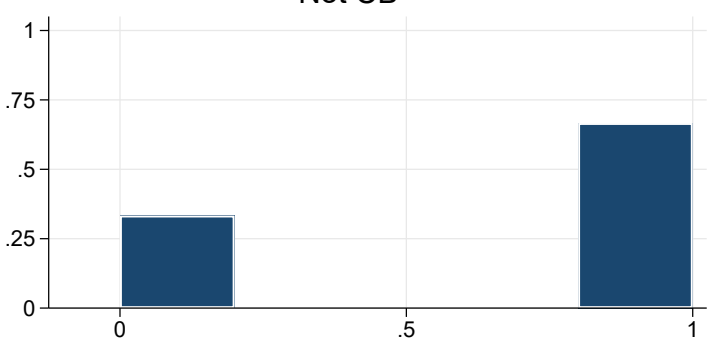

(D) Economic Significance: Inflation

Figure 7: Significance by Central Bank Affiliation. The figure plots histograms for the significance of the estimated effect on output and inflation, separately for papers with and without CB-affiliated authors. The panels show the statistical and economic significance of the QE program's estimated effect on output and inflation, respectively. Statistical significance is equal to one if the authors conclude that the effect of QE is positive and statistically significant, and zero otherwise. Economic significance is equal to one (zero) if the authors assess the effect of QE to be economically significant (insignificant); it is equal to 0.5 if the authors conclude the economic effect is moderate. 

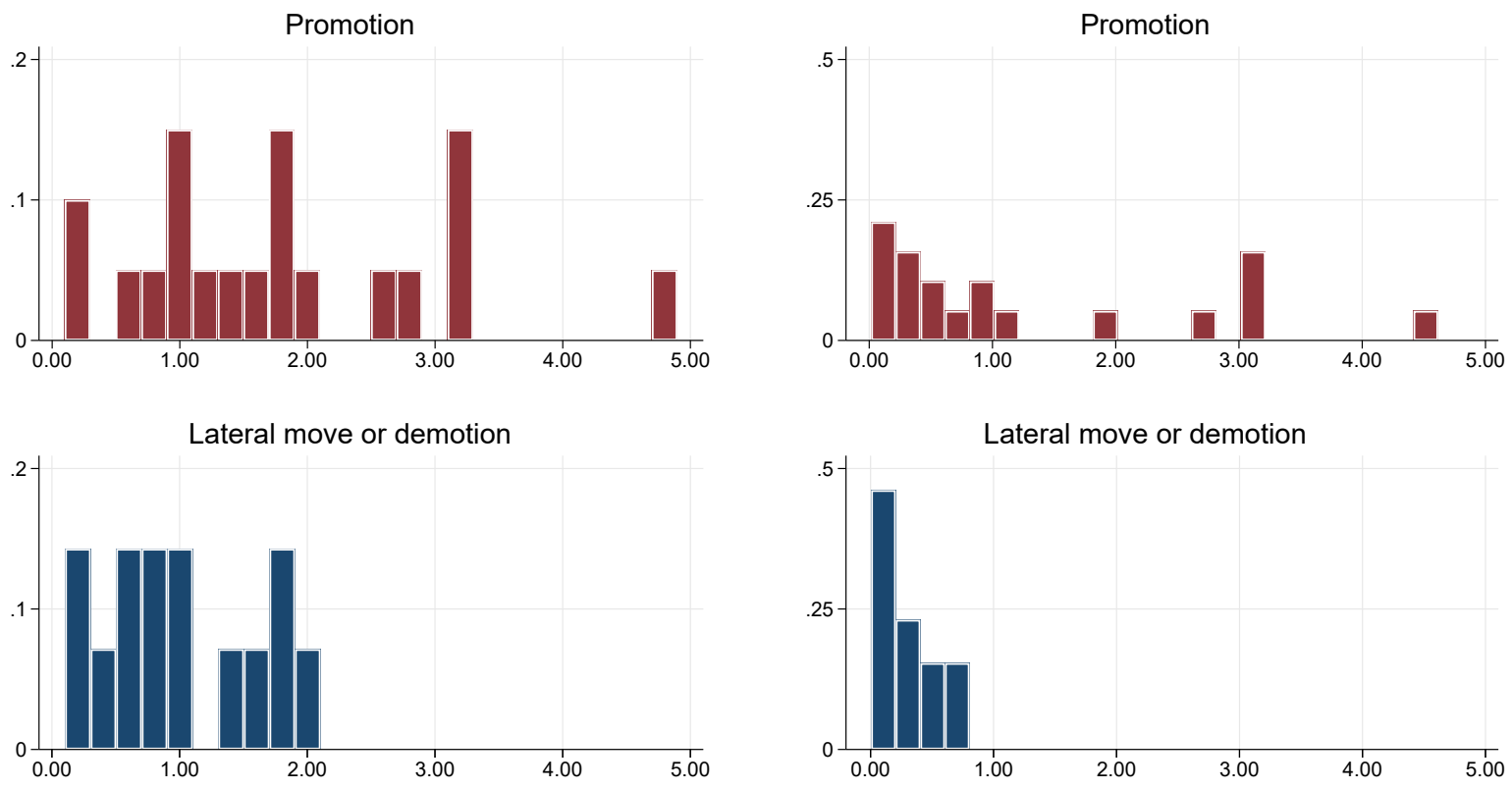

(A) Total Peak Effect

(B) Total Cumulative Effect

Promotion
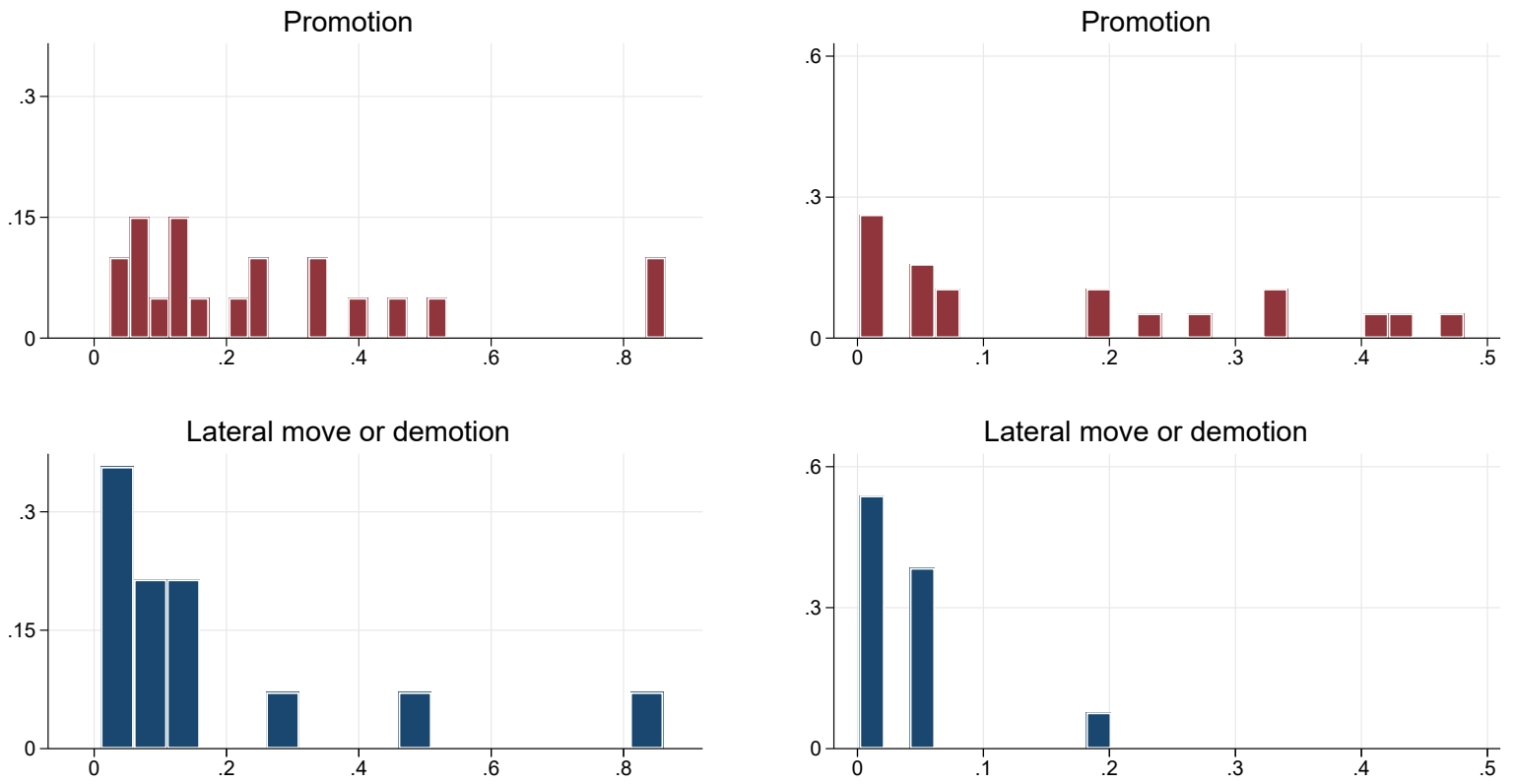

(C) Standardized Peak Effect

(D) Standardized Cumulative Effect

Figure 8: Career Outcomes and the Effect on Output. The figure plots histograms for the estimated effect on output by the author's subsequent career path. We restrict the sample to authors who remain affiliated with a central bank and experience at least one career update. Panels A and B show the total estimated peak and cumulative effects of the QE program studied on the output level, respectively. Panels $\mathrm{C}$ and D show the estimated peak and cumulative effects on the output level, after standardizing the QE shock size to $1 \%$ of GDP. The unit of observation is at the author-paper-country level. 


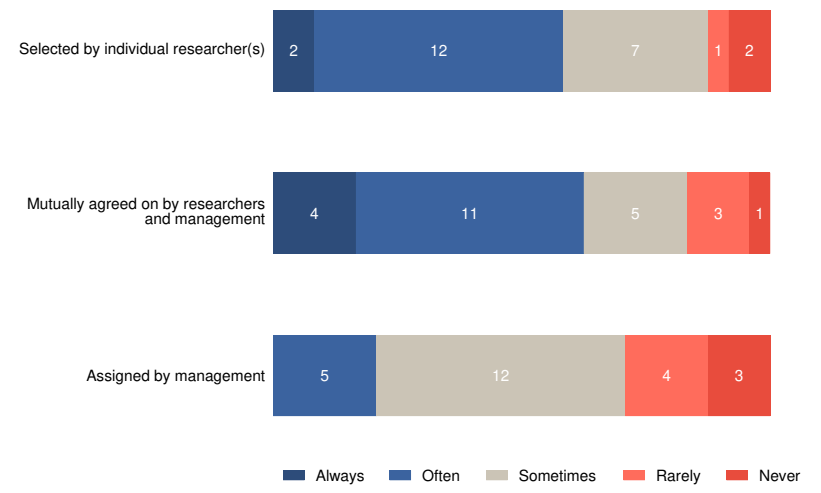

(A) How are research topics selected in your central bank?

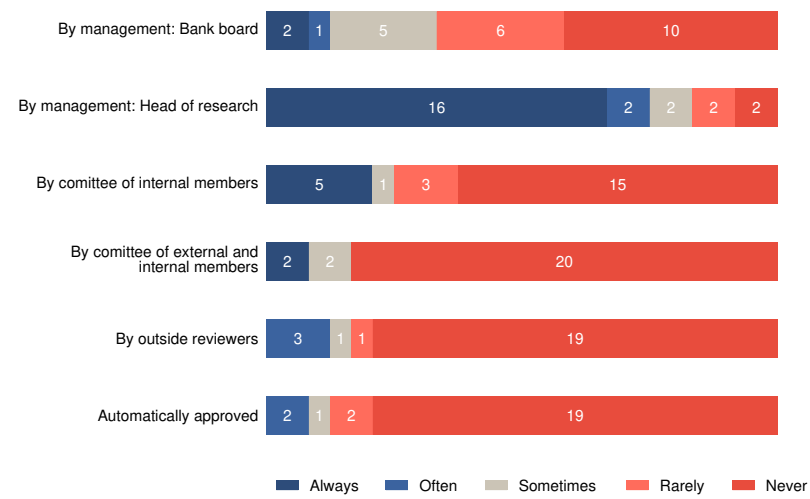

(C) How are your institution's draft research papers approved for public distribution?

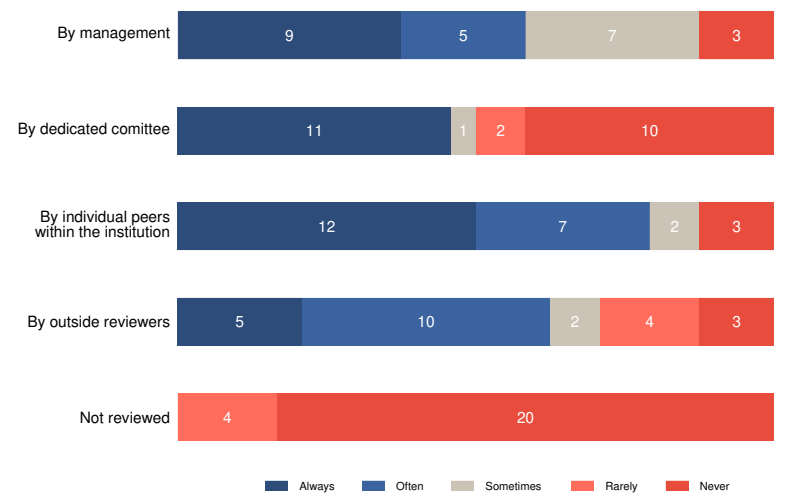

(B) How are draft research papers reviewed / commented on in your institution, prior to their public distribution?

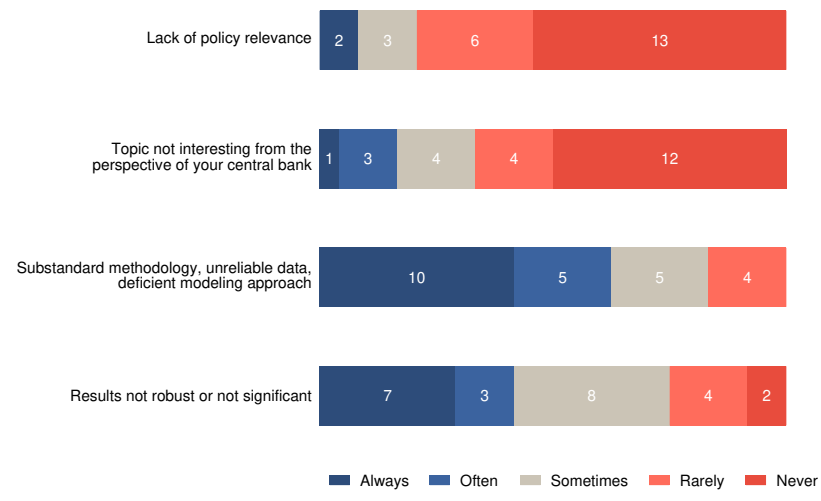

(D) What criteria can lead to the paper being rejected (i.e., not approved for public distribution)?

Figure 9: Survey of Central Banks. The figure reports survey responses of 24 central banks. 


\section{Table 1: Summary Statistics}

This table reports summary statistics for our sample of 54 research papers (Panel A) and 137 authors (Panel B).

\begin{tabular}{lcccc}
\hline \hline Variable & $\mathrm{N}$ & Mean & Median & SD \\
\hline Panel A: Paper-Level Variables & & & & \\
Number of authors & 54 & 2.537 & 2.000 & 0.985 \\
Number of countries studied & 54 & 1.259 & 1.000 & 0.589 \\
DSGE & 54 & 0.352 & 0.000 & 0.482 \\
Sentiment score in abstract & 54 & 0.044 & 0.047 & 0.066 \\
Published & 54 & 0.574 & 1.000 & 0.499 \\
Impact factor & 29 & 1.423 & 1.268 & 0.873 \\
& & & & \\
Panel B: Author-Level Variables & & & & \\
CB affiliation & 137 & 0.602 & 1.000 & 0.478 \\
Female & 137 & 0.168 & 0.000 & 0.375 \\
Author experience & 127 & 10.992 & 9.000 & 9.861 \\
PhD degree & 137 & 0.891 & 1.000 & 0.313 \\
Seniority & 114 & 3.193 & 3.000 & 1.708 \\
Years since last career update & 125 & 3.896 & 3.000 & 4.097 \\
\hline \hline
\end{tabular}




\section{Table 2: The Effect of QE on Output and Inflation}

This table reports the mean, median (in square brackets), and standard deviation (in parentheses) for the estimated effects of $\mathrm{QE}$ on output and inflation, as well as for indicators of statistical significance. We always report the effect on the output level or price level, in percent. Standardized effects refer to the effect of a QE shock size equivalent to $1 \%$ of GDP. The statistics are reported for the full sample $(\mathrm{All})$ and for studies of QE in the U.S., UK, and EA. The unit of observation is the paper-country.

\begin{tabular}{|c|c|c|c|c|}
\hline & All & US & UK & EA \\
\hline \multicolumn{5}{|l|}{ Panel A: Effect on Output } \\
\hline \multirow[t]{3}{*}{ Peak effect on output } & 1.57 & 1.25 & 1.67 & 1.77 \\
\hline & {$[1.25]$} & {$[1.01]$} & {$[1.30]$} & {$[1.41]$} \\
\hline & $(1.21)$ & $(0.92)$ & $(1.22)$ & $(1.41)$ \\
\hline \multirow[t]{3}{*}{ Standardized peak effect on output } & 0.24 & 0.36 & 0.12 & 0.22 \\
\hline & {$[0.16]$} & {$[0.23]$} & {$[0.10]$} & {$[0.15]$} \\
\hline & $(0.28)$ & $(0.35)$ & $(0.09)$ & $(0.27)$ \\
\hline \multirow[t]{3}{*}{ Cumulative effect on output } & 0.87 & 0.59 & 0.68 & 1.24 \\
\hline & {$[0.40]$} & {$[0.35]$} & {$[0.49]$} & {$[0.37]$} \\
\hline & $(1.23)$ & $(0.93)$ & $(0.77)$ & $(1.62)$ \\
\hline \multirow[t]{3}{*}{ Standardized cumulative effect on output } & 0.14 & 0.17 & 0.05 & 0.16 \\
\hline & {$[0.04]$} & {$[0.06]$} & {$[0.03]$} & {$[0.04]$} \\
\hline & $(0.26)$ & $(0.33)$ & $(0.06)$ & $(0.29)$ \\
\hline \multicolumn{5}{|l|}{ Panel B: Effect on Inflation } \\
\hline \multirow[t]{3}{*}{ Peak effect on inflation } & 1.42 & 1.07 & 2.14 & 1.25 \\
\hline & {$[0.93]$} & {$[0.77]$} & {$[1.03]$} & {$[0.96]$} \\
\hline & $(1.52)$ & $(0.99)$ & $(2.36)$ & $(1.02)$ \\
\hline \multirow[t]{3}{*}{ Standardized peak effect on inflation } & 0.19 & 0.30 & 0.15 & 0.12 \\
\hline & {$[0.11]$} & {$[0.18]$} & {$[0.08]$} & {$[0.10]$} \\
\hline & $(0.24)$ & $(0.36)$ & $(0.14)$ & $(0.10)$ \\
\hline \multirow[t]{3}{*}{ Cumulative effect on inflation } & 0.89 & 0.78 & 0.77 & 1.07 \\
\hline & {$[0.75]$} & {$[0.58]$} & {$[0.74]$} & {$[0.85]$} \\
\hline & $(1.94)$ & $(1.03)$ & $(3.44)$ & $(1.08)$ \\
\hline \multirow[t]{3}{*}{ Standardized cumulative effect on inflation } & 0.12 & 0.21 & 0.04 & 0.11 \\
\hline & {$[0.08]$} & {$[0.13]$} & {$[0.06]$} & {$[0.08]$} \\
\hline & $(0.26)$ & $(0.37)$ & $(0.23)$ & $(0.11)$ \\
\hline \multicolumn{5}{|l|}{ Panel C: Significance } \\
\hline \multirow[t]{3}{*}{ Statistical significance: output } & 0.88 & 0.92 & 0.73 & 0.94 \\
\hline & {$[1.00]$} & {$[1.00]$} & {$[1.00]$} & {$[1.00]$} \\
\hline & $(0.33)$ & $(0.28)$ & $(0.47)$ & $(0.24)$ \\
\hline \multirow[t]{3}{*}{ Statistical significance: inflation } & 0.84 & 0.92 & 0.67 & 0.88 \\
\hline & {$[1.00]$} & {$[1.00]$} & {$[1.00]$} & {$[1.00]$} \\
\hline & $(0.37)$ & $(0.28)$ & $(0.50)$ & $(0.34)$ \\
\hline
\end{tabular}




\section{Table 3: The Effect of QE on Output and Inflation by Central Bank Affiliation}

This table reports the means and medians (in parentheses) for the estimated effects of QE on output and inflation, as well as for indicators of statistical significance, separately for papers with and without CB-affiliated authors. We always report the effect on the output level or price level, in percent. Standardized effects refer to the effect of a QE shock size equivalent to 1\% of GDP. The All column is identical to the means and medians reported in the first column of Table 2. The unit of observation is the paper-country.

\begin{tabular}{lccc}
\hline \hline & All & CB & Not CB \\
\hline Panel A: Effect on Output & & & \\
Peak effect on output & 1.57 & 1.75 & 1.00 \\
& $(1.25)$ & $(1.53)$ & $(1.00)$ \\
Standardized peak effect on output & 0.24 & 0.28 & 0.11 \\
& $(0.16)$ & $(0.18)$ & $(0.10)$ \\
Cumulative effect on output & 0.87 & 1.06 & 0.48 \\
& $(0.40)$ & $(0.42)$ & $(0.05)$ \\
Standardized cumulative effect on output & 0.14 & 0.18 & 0.04 \\
& $(0.04)$ & $(0.06)$ & $(0.01)$ \\
Panel B: Effect on Inflation & & & \\
Peak effect on inflation & 1.42 & 1.79 & 0.54 \\
& $(0.93)$ & $(1.17)$ & $(0.40)$ \\
Standardized peak effect on inflation & 0.19 & 0.24 & 0.05 \\
& $(0.11)$ & $(0.15)$ & $(0.04)$ \\
Cumulative effect on inflation & 0.89 & 1.35 & -0.21 \\
& $(0.75)$ & $(0.82)$ & $(0.14)$ \\
Standardized cumulative effect on inflation & 0.12 & 0.18 & -0.01 \\
& $(0.08)$ & $(0.11)$ & $(0.01)$ \\
Panel C: Significance & & & \\
Statistical significance: output & 0.88 & 1.00 & 0.50 \\
Statistical significance: inflation & $(1.00)$ & $(1.00)$ & $(0.50)$ \\
& 0.84 & 0.89 & 0.75 \\
\hline \hline
\end{tabular}




\section{Table 4: The Effect of QE on Output}

This table regresses the estimated effect of QE on output on the share of authors with central bank affiliation. In Panel A, we use the total estimated effect of the QE program studied on the level of output. Panel B uses the estimated effect on the level of output, after standardizing the QE shock size to $1 \%$ of GDP. Controls include the number of authors and the logarithm of three plus the average author experience. $t$-statistics, reported in parentheses, are based on standard errors clustered at the paper level. $p$-values obtained using the wild cluster bootstrap procedure $(10,000$ repetitions) are reported in square brackets. The unit of observation is the paper-country.

Panel A: Total Program Effect

\begin{tabular}{|c|c|c|c|c|c|c|}
\hline & \multicolumn{3}{|c|}{ Peak Effect } & \multicolumn{3}{|c|}{ Cumulative Effect } \\
\hline & (1) & (2) & (3) & (4) & (5) & (6) \\
\hline \multirow[t]{3}{*}{ CB Affiliation } & 0.789 & 0.770 & 0.723 & 0.620 & 0.526 & 0.512 \\
\hline & $(2.16)$ & $(2.17)$ & $(1.83)$ & $(1.60)$ & $(1.51)$ & $(1.36)$ \\
\hline & {$[0.041]$} & {$[0.038]$} & {$[0.085]$} & {$[0.115]$} & {$[0.134]$} & {$[0.167]$} \\
\hline Country FE & & $\mathrm{X}$ & $\mathrm{X}$ & & $\mathrm{X}$ & $\mathrm{X}$ \\
\hline Controls & & & $\mathrm{X}$ & & & $\mathrm{X}$ \\
\hline Observations & 58 & 58 & 58 & 57 & 57 & 57 \\
\hline$R^{2}$ & 0.072 & 0.103 & 0.112 & 0.043 & 0.091 & 0.096 \\
\hline
\end{tabular}

Panel B: Standardized Effect

\begin{tabular}{lcccccc}
\hline \hline & \multicolumn{3}{c}{ Peak Effect } & \multicolumn{3}{c}{ Cumulative Effect } \\
\cline { 2 - 7 } & $(1)$ & $(2)$ & $(3)$ & $(4)$ & $(5)$ & $(6)$ \\
\hline CB Affiliation & 0.164 & 0.163 & 0.152 & 0.140 & 0.127 & 0.122 \\
& $(2.38)$ & $(2.48)$ & $(2.11)$ & $(2.17)$ & $(2.17)$ & $(1.90)$ \\
& {$[0.021]$} & {$[0.018]$} & {$[0.052]$} & {$[0.021]$} & {$[0.020]$} & {$[0.049]$} \\
\hline Country FE & & $\mathrm{X}$ & $\mathrm{X}$ & & $\mathrm{X}$ & $\mathrm{X}$ \\
Controls & & & $\mathrm{X}$ & & & $\mathrm{X}$ \\
Observations & 58 & 58 & 58 & 57 & 57 & 57 \\
$R^{2}$ & 0.060 & 0.170 & 0.206 & 0.048 & 0.078 & 0.106 \\
\hline \hline
\end{tabular}




\section{Table 5: The Effect of QE on Inflation}

This table regresses the estimated effect of QE on inflation on the share of authors with central bank affiliation. In Panel A, we use the total estimated effect of the QE program studied on the price level. Panel B uses the estimated effect on the price level, after standardizing the QE shock size to $1 \%$ of GDP. Controls include the number of authors and the logarithm of three plus the average author experience. $t$-statistics, reported in parentheses, are based on standard errors clustered at the paper level. $p$-values obtained using the wild cluster bootstrap procedure (10,000 repetitions) are reported in square brackets. The unit of observation is at the paper-country level.

Panel A: Total Program Effect

\begin{tabular}{|c|c|c|c|c|c|c|}
\hline & \multicolumn{3}{|c|}{ Peak Effect } & \multicolumn{3}{|c|}{ Cumulative Effect } \\
\hline & (1) & $(2)$ & (3) & (4) & (5) & $(6)$ \\
\hline \multirow[t]{3}{*}{ CB Affiliation } & 1.409 & 1.493 & 1.279 & 1.700 & 1.687 & 1.394 \\
\hline & $(3.42)$ & $(3.33)$ & $(2.79)$ & $(2.24)$ & $(2.20)$ & $(2.04)$ \\
\hline & {$[0.002]$} & {$[0.002]$} & {$[0.011]$} & {$[0.011]$} & {$[0.013]$} & {$[0.044]$} \\
\hline Country FE & & $\mathrm{X}$ & $\mathrm{X}$ & & $\mathrm{X}$ & $\mathrm{X}$ \\
\hline Controls & & & $\mathrm{X}$ & & & $\mathrm{X}$ \\
\hline Observations & 53 & 53 & 53 & 53 & 53 & 53 \\
\hline$R^{2}$ & 0.142 & 0.239 & 0.298 & 0.126 & 0.126 & 0.195 \\
\hline
\end{tabular}

Panel B: Standardized Effect

\begin{tabular}{|c|c|c|c|c|c|c|}
\hline & \multicolumn{3}{|c|}{ Peak Effect } & \multicolumn{3}{|c|}{ Cumulative Effect } \\
\hline & (1) & $(2)$ & (3) & (4) & $(5)$ & (6) \\
\hline \multirow[t]{3}{*}{ CB Affiliation } & 0.197 & 0.227 & 0.201 & 0.205 & 0.220 & 0.190 \\
\hline & $(2.61)$ & $(2.73)$ & $(2.73)$ & $(2.31)$ & $(2.31)$ & $(2.41)$ \\
\hline & {$[0.007]$} & {$[0.005]$} & {$[0.004]$} & {$[0.004]$} & {$[0.004]$} & {$[0.007]$} \\
\hline Country FE & & $\mathrm{X}$ & $\mathrm{X}$ & & $\mathrm{X}$ & $\mathrm{X}$ \\
\hline Controls & & & $\mathrm{X}$ & & & $\mathrm{X}$ \\
\hline Observations & 53 & 53 & 53 & 53 & 53 & 53 \\
\hline$R^{2}$ & 0.110 & 0.248 & 0.296 & 0.106 & 0.186 & 0.226 \\
\hline
\end{tabular}




\section{Table 6: Significance}

This table regresses the statistical and economic significance of the estimated effect of QE on output and inflation on the share of central bank affiliated authors. In Panel A (B), the dependent variable is the reported statistical and economic significance of the effect on output (inflation). Controls include the number of authors and the logarithm of three plus the average author experience. $t$-statistics, reported in parentheses, are based on standard errors clustered at the paper level. $p$-values obtained using the wild cluster bootstrap procedure (10,000 repetitions) are reported in square brackets. The unit of observation is the paper-country.

Panel A: Effect on Output

\begin{tabular}{|c|c|c|c|c|c|c|}
\hline & \multicolumn{3}{|c|}{ Statistical Significance } & \multicolumn{3}{|c|}{ Economic Significance } \\
\hline & (1) & $(2)$ & (3) & (4) & (5) & $(6)$ \\
\hline \multirow[t]{3}{*}{ CB Affiliation } & 0.412 & 0.388 & 0.366 & 0.335 & 0.344 & 0.399 \\
\hline & $(2.42)$ & $(2.41)$ & $(2.20)$ & $(2.78)$ & $(2.78)$ & $(3.42)$ \\
\hline & {$[0.041]$} & {$[0.035]$} & {$[0.043]$} & {$[0.019]$} & {$[0.019]$} & {$[0.005]$} \\
\hline Country FE & & $\mathrm{X}$ & $\mathrm{X}$ & & $\mathrm{X}$ & $\mathrm{X}$ \\
\hline Controls & & & $\mathrm{X}$ & & & $\mathrm{X}$ \\
\hline Observations & 41 & 41 & 41 & 66 & 66 & 66 \\
\hline$R^{2}$ & 0.233 & 0.280 & 0.298 & 0.139 & 0.145 & 0.250 \\
\hline
\end{tabular}

Panel B: Effect on Inflation

\begin{tabular}{|c|c|c|c|c|c|c|}
\hline & \multicolumn{3}{|c|}{ Statistical Significance } & \multicolumn{3}{|c|}{ Economic Significance } \\
\hline & (1) & $(2)$ & (3) & (4) & $(5)$ & (6) \\
\hline \multirow[t]{3}{*}{ CB Affiliation } & 0.202 & 0.202 & 0.164 & 0.196 & 0.207 & 0.248 \\
\hline & $(1.18)$ & $(1.25)$ & $(1.11)$ & $(1.29)$ & $(1.36)$ & $(1.86)$ \\
\hline & {$[0.339]$} & {$[0.283]$} & {$[0.372]$} & {$[0.222]$} & {$[0.197]$} & {$[0.093]$} \\
\hline Country FE & & $\mathrm{X}$ & $\mathrm{X}$ & & $\mathrm{X}$ & $\mathrm{X}$ \\
\hline Controls & & & $\mathrm{X}$ & & & $\mathrm{X}$ \\
\hline Observations & 38 & 38 & 38 & 60 & 60 & 60 \\
\hline$R^{2}$ & 0.044 & 0.118 & 0.208 & 0.041 & 0.043 & 0.137 \\
\hline
\end{tabular}




\section{Table 7: Tone in Abstract}

This table regresses measures of the tone of the paper's abstract on the share of central bank affiliated authors. In Panel A, the dependent variable is the sentiment score, computed as the difference in the percentage of positive and negative adjectives in the abstract. In Panel B (C), the dependent variable is the percentage of positive (negative) adjectives in the abstract. Controls include the number of authors and the logarithm of three plus the average author experience. $t$ statistics, reported in parentheses, are based on robust standard errors. p-values obtained using the wild cluster bootstrap procedure (10,000 repetitions) are reported in square brackets. The unit of observation is the paper.

Panel A: Sentiment Score

\begin{tabular}{lccc}
\hline \hline & $(1)$ & $(2)$ & $(3)$ \\
\hline CB Affiliation & 0.046 & 0.053 & 0.056 \\
& $(2.05)$ & $(2.59)$ & $(2.60)$ \\
& {$[0.049]$} & {$[0.014]$} & {$[0.013]$} \\
\hline Country Dummies & & $\mathrm{X}$ & $\mathrm{X}$ \\
Controls & & & $\mathrm{X}$ \\
Observations & 54 & 54 & 54 \\
$R^{2}$ & 0.081 & 0.129 & 0.133 \\
\hline \hline
\end{tabular}

Panel B: Percentage of Positive Adjectives

\begin{tabular}{lccc}
\hline \hline & $(1)$ & $(2)$ & $(3)$ \\
\hline CB Affiliation & 0.033 & 0.040 & 0.043 \\
& $(1.61)$ & $(2.15)$ & $(2.22)$ \\
& {$[0.125]$} & {$[0.043]$} & {$[0.030]$} \\
\hline Country Dummies & & $\mathrm{X}$ & $\mathrm{X}$ \\
Controls & & & $\mathrm{X}$ \\
Observations & 54 & 54 & 54 \\
$R^{2}$ & 0.052 & 0.128 & 0.136 \\
\hline \hline
\end{tabular}

Panel C: Percentage of Negative Adjectives

\begin{tabular}{lccc}
\hline \hline & $(1)$ & $(2)$ & $(3)$ \\
\hline CB Affiliation & -0.013 & -0.013 & -0.013 \\
& $(-1.35)$ & $(-1.22)$ & $(-1.16)$ \\
& {$[0.197]$} & {$[0.252]$} & {$[0.272]$} \\
\hline Country Dummies & & $\mathrm{X}$ & $\mathrm{X}$ \\
Controls & & & $\mathrm{X}$ \\
Observations & 54 & 54 & 54 \\
$R^{2}$ & 0.040 & 0.048 & 0.052 \\
\hline \hline
\end{tabular}




\section{Table 8: Career Outcomes and the Effect of QE on Output}

This table regresses career outcomes on the author's estimated effect of QE on output. The dependent variable is the difference between the author's rank after her first career update following the paper's first circulation, and her rank at the time of first circulation. In Panel A, we use the total estimated effect of the QE program studied on the level of output. In Panel B, the QE shock size is standardized to $1 \%$ of GDP. Controls include the number of authors, the logarithm of three plus the researcher's experience, the number of years since the author's last career update, as well as dummy variables indicating the author's rank at the time of the paper's first circulation. We restrict the sample to authors who remain affiliated with a central bank and experience at least one career update after the paper's first circulation. $t$-statistics, reported in parentheses, are based on standard errors clustered at the author level. $p$-values obtained using the wild cluster bootstrap procedure (10,000 repetitions) are reported in square brackets. The unit of observation is the author-paper-country.

Panel A: Total Program Effect

\begin{tabular}{|c|c|c|c|c|c|c|}
\hline & \multicolumn{3}{|c|}{ Peak Effect } & \multicolumn{3}{|c|}{ Cumulative Effect } \\
\hline & (1) & $(2)$ & (3) & $(4)$ & (5) & (6) \\
\hline \multirow[t]{3}{*}{ Effect on output } & 0.264 & 0.219 & 0.485 & 0.204 & 0.204 & 0.460 \\
\hline & $(2.32)$ & $(1.85)$ & $(2.65)$ & $(1.78)$ & $(1.25)$ & $(2.12)$ \\
\hline & {$[0.027]$} & {$[0.037]$} & {$[0.018]$} & {$[0.079]$} & {$[0.234]$} & {$[0.019]$} \\
\hline Country FE & & $\mathrm{X}$ & $\mathrm{X}$ & & $\mathrm{X}$ & $\mathrm{X}$ \\
\hline Controls & & & $\mathrm{X}$ & & & $\mathrm{X}$ \\
\hline Observations & 34 & 34 & 31 & 32 & 32 & 30 \\
\hline$R^{2}$ & 0.030 & 0.066 & 0.553 & 0.027 & 0.076 & 0.550 \\
\hline
\end{tabular}

Panel B: Standardized Effect

\begin{tabular}{lcccccccc}
\hline \hline & \multicolumn{3}{c}{ Peak Effect } & & \multicolumn{3}{c}{ Cumulative Effect } \\
\cline { 2 - 4 } \cline { 7 - 9 } & $(1)$ & $(2)$ & $(3)$ & & $(4)$ & $(5)$ & $(6)$ \\
\hline Effect on output & 1.407 & 1.009 & 2.661 & & 2.311 & 1.838 & 4.095 \\
& $(1.41)$ & $(1.15)$ & $(1.86)$ & & $(2.00)$ & $(1.45)$ & $(2.15)$ \\
& {$[0.231]$} & {$[0.356]$} & {$[0.082]$} & & {$[0.041]$} & {$[0.134]$} & {$[0.022]$} \\
\hline Country FE & & $\mathrm{X}$ & $\mathrm{X}$ & & & $\mathrm{X}$ & $\mathrm{X}$ \\
Controls & & & $\mathrm{X}$ & & & $\mathrm{X}$ \\
Observations & 34 & 34 & 31 & & 32 & 32 & 30 \\
$R^{2}$ & 0.044 & 0.062 & 0.553 & & 0.051 & 0.081 & 0.569 \\
\hline \hline
\end{tabular}




\section{Table 9: Career Outcomes, the Effects of QE, and Author Seniority}

This table repeats the analysis in Table 8, after adding an interaction between the estimated effects on output and inflation and author seniority, which is standardized to have a mean of zero and a standard deviation of one. $t$-statistics, reported in parentheses, are based on standard errors clustered at the author level. $p$-values obtained using the wild cluster bootstrap procedure $(10,000$ repetitions) are reported in square brackets. The unit of observation is the author-paper-country.

Panel A: Effect on Output

\begin{tabular}{|c|c|c|c|c|}
\hline & \multicolumn{2}{|c|}{ Total Program Effect } & \multicolumn{2}{|c|}{ Standardized Effect } \\
\hline & $\begin{array}{l}\text { Peak } \\
(1)\end{array}$ & $\begin{array}{c}\text { Cumulative } \\
\text { (2) }\end{array}$ & $\begin{array}{c}\text { Peak } \\
(3)\end{array}$ & $\begin{array}{c}\text { Cumulative } \\
\text { (4) }\end{array}$ \\
\hline \multirow[t]{3}{*}{ Effect on output } & 0.802 & 0.808 & 3.686 & 7.380 \\
\hline & $(2.78)$ & $(3.22)$ & $(6.42)$ & $(4.48)$ \\
\hline & {$[0.050]$} & {$[0.005]$} & {$[0.003]$} & {$[0.002]$} \\
\hline \multirow{3}{*}{ Effect on output $\times$ Seniority } & 0.364 & 0.375 & 2.079 & 4.108 \\
\hline & $(2.02)$ & $(2.75)$ & $(4.43)$ & $(3.15)$ \\
\hline & {$[0.062]$} & {$[0.005]$} & {$[0.044]$} & {$[0.005]$} \\
\hline \multirow[t]{3}{*}{ Seniority } & -1.831 & -1.559 & -2.365 & -1.999 \\
\hline & $(-2.78)$ & $(-2.68)$ & $(-5.12)$ & $(-4.79)$ \\
\hline & {$[0.062]$} & {$[0.058]$} & {$[0.052]$} & {$[0.010]$} \\
\hline Country FE + Controls & $\mathrm{X}$ & $\mathrm{X}$ & $\mathrm{X}$ & $\mathrm{X}$ \\
\hline Observations & 31 & 30 & 31 & 30 \\
\hline$R^{2}$ & 0.594 & 0.612 & 0.648 & 0.676 \\
\hline \multicolumn{5}{|l|}{ Panel B: Effect on Inflation } \\
\hline & \multicolumn{2}{|c|}{ Total Program Effect } & \multicolumn{2}{|c|}{ Standardized Effect } \\
\hline & $\begin{array}{l}\text { Peak } \\
(1)\end{array}$ & $\begin{array}{c}\text { Cumulative } \\
(2)\end{array}$ & $\begin{array}{c}\text { Peak } \\
(3)\end{array}$ & $\begin{array}{c}\text { Cumulative } \\
\text { (4) }\end{array}$ \\
\hline \multirow[t]{3}{*}{ Effect on inflation } & -0.414 & -0.235 & 1.887 & 1.912 \\
\hline & $(-1.01)$ & $(-0.72)$ & $(4.84)$ & $(5.29)$ \\
\hline & {$[0.454]$} & {$[0.579]$} & {$[0.109]$} & {$[0.068]$} \\
\hline \multirow[t]{3}{*}{ Effect on inflation $\times$ Seniority } & -0.360 & -0.158 & 1.720 & 1.720 \\
\hline & $(-0.84)$ & $(-0.46)$ & $(6.89)$ & $(7.53)$ \\
\hline & {$[0.564]$} & {$[0.745]$} & {$[0.095]$} & {$[0.057]$} \\
\hline \multirow[t]{3}{*}{ Seniority } & -0.298 & -0.909 & -3.000 & -2.997 \\
\hline & $(-0.20)$ & $(-0.69)$ & $(-6.40)$ & $(-6.72)$ \\
\hline & {$[0.881]$} & {$[0.597]$} & {$[0.055]$} & {$[0.045]$} \\
\hline Country FE + Controls & $\mathrm{X}$ & $\mathrm{X}$ & $\mathrm{X}$ & $\mathrm{X}$ \\
\hline Observations & 29 & 29 & 29 & 29 \\
\hline$R^{2}$ & 0.515 & 0.486 & 0.633 & 0.639 \\
\hline
\end{tabular}




\section{Table 10: Author Seniority and the Effects of QE}

This table repeats the analysis in Tables 4 to 6 , after adding an interaction between central bank affiliation and the rank of the most senior author on the team, which is standardized to have a mean of zero and a standard deviation of one. $t$-statistics, reported in parentheses, are based on standard errors clustered at the paper level. $p$-values obtained using the wild cluster bootstrap procedure (10,000 repetitions) are reported in square brackets. The unit of observation is the paper.

Panel A: Effect on Output

\begin{tabular}{|c|c|c|c|c|}
\hline & \multicolumn{2}{|c|}{ Total Program Effect } & \multicolumn{2}{|c|}{ Standardized Effect } \\
\hline & $\begin{array}{c}\text { Peak } \\
(1)\end{array}$ & $\begin{array}{c}\text { Cumulative } \\
\text { (2) }\end{array}$ & $\begin{array}{c}\text { Peak } \\
(3)\end{array}$ & $\begin{array}{c}\text { Cumulative } \\
\text { (4) }\end{array}$ \\
\hline \multirow[t]{3}{*}{ CB Affiliation } & 0.673 & 0.599 & 0.105 & 0.117 \\
\hline & $(1.62)$ & $(1.65)$ & $(1.34)$ & $(1.74)$ \\
\hline & {$[0.144]$} & {$[0.094]$} & {$[0.222]$} & {$[0.076]$} \\
\hline \multirow[t]{3}{*}{ CB Affiliation $\times$ Max Seniority } & 1.054 & 1.036 & 0.152 & 0.145 \\
\hline & $(2.01)$ & $(1.67)$ & $(1.32)$ & $(1.23)$ \\
\hline & {$[0.087]$} & {$[0.185]$} & {$[0.224]$} & {$[0.281]$} \\
\hline \multirow[t]{3}{*}{ Max Seniority } & -0.615 & -0.707 & -0.053 & -0.087 \\
\hline & $(-1.64)$ & $(-1.69)$ & $(-0.69)$ & $(-1.14)$ \\
\hline & {$[0.165]$} & {$[0.259]$} & {$[0.516]$} & {$[0.315]$} \\
\hline Country FE + Controls & $\mathrm{X}$ & $\mathrm{X}$ & $\mathrm{X}$ & $\mathrm{X}$ \\
\hline Observations & 56 & 55 & 56 & 55 \\
\hline$R^{2}$ & 0.171 & 0.145 & 0.258 & 0.133 \\
\hline
\end{tabular}

Panel B: Effect on Inflation

\begin{tabular}{|c|c|c|c|c|}
\hline & \multicolumn{2}{|c|}{ Total Program Effect } & \multicolumn{2}{|c|}{ Standardized Effect } \\
\hline & $\begin{array}{l}\text { Peak } \\
(1)\end{array}$ & $\begin{array}{c}\text { Cumulative } \\
(2)\end{array}$ & $\begin{array}{c}\text { Peak } \\
(3)\end{array}$ & $\begin{array}{c}\text { Cumulative } \\
\text { (4) }\end{array}$ \\
\hline \multirow[t]{3}{*}{ CB Affiliation } & 1.747 & 2.061 & 0.215 & 0.231 \\
\hline & $(2.97)$ & $(2.21)$ & $(2.56)$ & $(2.30)$ \\
\hline & {$[0.005]$} & {$[0.038]$} & {$[0.012]$} & {$[0.014]$} \\
\hline \multirow[t]{3}{*}{ CB Affiliation $\times$ Max Seniority } & 1.140 & 0.499 & 0.197 & 0.131 \\
\hline & $(2.36)$ & $(0.85)$ & $(1.89)$ & $(1.16)$ \\
\hline & {$[0.027]$} & {$[0.324]$} & {$[0.090]$} & {$[0.267]$} \\
\hline \multirow[t]{3}{*}{ Max Seniority } & -1.033 & -0.903 & -0.107 & -0.103 \\
\hline & $(-2.48)$ & $(-1.96)$ & $(-1.59)$ & $(-1.46)$ \\
\hline & {$[0.030]$} & {$[0.049]$} & {$[0.140]$} & {$[0.122]$} \\
\hline Country FE + Controls & $\mathrm{X}$ & $\mathrm{X}$ & $\mathrm{X}$ & $\mathrm{X}$ \\
\hline Observations & 51 & 51 & 51 & 51 \\
\hline$R^{2}$ & 0.337 & 0.243 & 0.368 & 0.246 \\
\hline
\end{tabular}


Panel C: Significance

\begin{tabular}{lccccc}
\hline \hline & \multicolumn{2}{c}{ Effect on Output } & & \multicolumn{2}{c}{ Effect on Inflation } \\
\cline { 2 - 3 } \cline { 5 - 6 } & Statistical & Economic & & Statistical & Economic \\
& $(1)$ & $(2)$ & & $(3)$ & $(4)$ \\
\hline CB Affiliation & 0.472 & 0.483 & & 0.234 & 0.235 \\
& $(2.02)$ & $(3.46)$ & & $(1.17)$ & $(1.46)$ \\
CB Affiliation $\times$ Max Seniority & {$[0.098]$} & {$[0.012]$} & & {$[0.313]$} & {$[0.206]$} \\
& 0.335 & 0.337 & & 0.336 & 0.173 \\
& $(2.27)$ & $(2.68)$ & & $(2.10)$ & $(1.07)$ \\
Max Seniority & {$[0.074]$} & {$[0.021]$} & & {$[0.116]$} & {$[0.376]$} \\
& -0.266 & -0.246 & & -0.212 & -0.089 \\
& $(-2.17)$ & $(-2.25)$ & & $(-1.58)$ & $(-0.65)$ \\
Country FE + Controls & {$[0.128]$} & {$[0.076]$} & & {$[0.249]$} & {$[0.585]$} \\
Observations & $\mathrm{X}$ & $\mathrm{X}$ & & $\mathrm{X}$ & $\mathrm{X}$ \\
$R^{2}$ & 36 & 61 & & 33 & 55 \\
\hline \hline
\end{tabular}




\section{Table 11: Type of Central Bank and the Effects of QE}

This table repeats the analysis in Tables 4 to 6 , after replacing the share of central bank authors by three indicators: German $C B$ is an indicator equal to one if at least one of the authors is employed at the Bundesbank; Other $E A C B$ is equal to one if at least one of the authors is employed at the $\mathrm{ECB}$ or at a euro area national central bank that is not the Bundesbank; Non-EA $C B$ is equal to one if at least one of the authors is from a central bank outside of the euro area or from the BIS. The omitted group is academics. $t$-statistics, reported in parentheses, are based on standard errors clustered at the paper level. $p$-values obtained using the wild cluster bootstrap procedure $(10,000$ repetitions) are reported in square brackets. The unit of observation is the paper-country.

Panel A: Effect on Output

\begin{tabular}{|c|c|c|c|c|}
\hline & \multicolumn{2}{|c|}{ Total Program Effect } & \multicolumn{2}{|c|}{ Standardized Effect } \\
\hline & $\begin{array}{l}\text { Peak } \\
(1)\end{array}$ & $\begin{array}{c}\text { Cumulative } \\
(2)\end{array}$ & $\begin{array}{l}\text { Peak } \\
(3)\end{array}$ & $\begin{array}{c}\text { Cumulative } \\
\text { (4) }\end{array}$ \\
\hline \multirow[t]{3}{*}{ German CB } & -0.884 & -1.171 & -0.082 & -0.116 \\
\hline & $(-2.17)$ & $(-2.61)$ & $(-1.05)$ & $(-1.52)$ \\
\hline & {$[0.166]$} & {$[0.139]$} & {$[0.368]$} & {$[0.222]$} \\
\hline \multirow[t]{3}{*}{ Other EA CB } & 0.444 & 0.648 & 0.142 & 0.143 \\
\hline & $(0.95)$ & $(1.59)$ & $(1.98)$ & $(1.97)$ \\
\hline & {$[0.349]$} & {$[0.096]$} & {$[0.021]$} & {$[0.084]$} \\
\hline \multirow[t]{3}{*}{ Non-EA CB } & 0.688 & 0.313 & 0.143 & 0.097 \\
\hline & $(1.90)$ & $(1.11)$ & $(2.38)$ & $(1.90)$ \\
\hline & {$[0.140]$} & {$[0.259]$} & {$[0.048]$} & {$[0.052]$} \\
\hline Country FE + Controls & $\mathrm{X}$ & $\mathrm{X}$ & $\mathrm{X}$ & $\mathrm{X}$ \\
\hline Observations & 58 & 57 & 58 & 57 \\
\hline$R^{2}$ & 0.127 & 0.140 & 0.222 & 0.129 \\
\hline
\end{tabular}


Panel B: Effect on Inflation

\begin{tabular}{|c|c|c|c|c|}
\hline & \multicolumn{2}{|c|}{ Total Program Effect } & \multicolumn{2}{|c|}{ Standardized Effect } \\
\hline & $\begin{array}{l}\text { Peak } \\
(1)\end{array}$ & $\begin{array}{c}\text { Cumulative } \\
\text { (2) }\end{array}$ & $\begin{array}{c}\text { Peak } \\
(3)\end{array}$ & $\begin{array}{c}\text { Cumulative } \\
\text { (4) }\end{array}$ \\
\hline \multirow[t]{3}{*}{ German CB } & 0.461 & 0.640 & 0.094 & 0.101 \\
\hline & $(0.96)$ & $(1.34)$ & $(1.82)$ & $(1.88)$ \\
\hline & {$[0.508]$} & {$[0.235]$} & {$[0.117]$} & {$[0.117]$} \\
\hline \multirow[t]{3}{*}{ Other EA CB } & 0.279 & 0.722 & 0.088 & 0.133 \\
\hline & $(0.62)$ & $(1.44)$ & $(1.60)$ & $(2.28)$ \\
\hline & {$[0.603]$} & {$[0.144]$} & {$[0.108]$} & {$[0.037]$} \\
\hline \multirow[t]{3}{*}{ Non-EA CB } & 0.908 & 0.926 & 0.141 & 0.104 \\
\hline & $(1.64)$ & $(1.18)$ & $(2.10)$ & $(1.51)$ \\
\hline & {$[0.224]$} & {$[0.311]$} & {$[0.088]$} & {$[0.178]$} \\
\hline Country FE + Controls & $\mathrm{X}$ & $\mathrm{X}$ & $\mathrm{X}$ & $\mathrm{X}$ \\
\hline Observations & 53 & 53 & 53 & 53 \\
\hline$R^{2}$ & 0.244 & 0.161 & 0.250 & 0.195 \\
\hline
\end{tabular}

Panel C: Significance

\begin{tabular}{|c|c|c|c|c|}
\hline & \multicolumn{2}{|c|}{ Effect on Output } & \multicolumn{2}{|c|}{ Effect on Inflation } \\
\hline & $\begin{array}{c}\text { Statistical } \\
\text { (1) }\end{array}$ & $\begin{array}{c}\text { Economic } \\
(2)\end{array}$ & $\begin{array}{c}\text { Statistical } \\
(3)\end{array}$ & $\begin{array}{c}\text { Economic } \\
(4)\end{array}$ \\
\hline \multirow[t]{3}{*}{ German CB } & 0.187 & 0.240 & -0.339 & -0.074 \\
\hline & $(1.04)$ & $(1.53)$ & $(-1.07)$ & $(-0.32)$ \\
\hline & {$[0.369]$} & {$[0.214]$} & {$[0.464]$} & {$[0.810]$} \\
\hline \multirow[t]{3}{*}{ Other EA CB } & 0.228 & 0.419 & 0.085 & 0.254 \\
\hline & $(1.39)$ & $(2.80)$ & $(0.81)$ & $(2.16)$ \\
\hline & {$[0.151]$} & {$[0.002]$} & {$[0.391]$} & {$[0.038]$} \\
\hline \multirow[t]{3}{*}{ Non-EA CB } & 0.440 & 0.206 & 0.167 & 0.188 \\
\hline & $(2.81)$ & $(1.46)$ & $(0.97)$ & $(1.26)$ \\
\hline & {$[0.039]$} & {$[0.247]$} & {$[0.736]$} & {$[0.312]$} \\
\hline Country FE + Controls & $\mathrm{X}$ & $\mathrm{X}$ & $\mathrm{X}$ & $\mathrm{X}$ \\
\hline Observations & 41 & 66 & 38 & 60 \\
\hline$R^{2}$ & 0.457 & 0.256 & 0.298 & 0.167 \\
\hline
\end{tabular}




\section{Table 12: Methodological Choices}

This table regresses methodological choices on the share of central bank affiliated authors. In Panel A, columns (1) to (3), the dependent variable is an indicator equal to one if the paper does not specify the width of the confidence interval. In columns (4) to (6), the dependent variable is an indicator equal to one if the paper uses a $68 \%$ confidence interval or does not specify the width of the confidence interval, and zero if it uses a $90 \%$ or $95 \%$ confidence interval. We restrict the sample to papers that assess the statistical significance of the effect on either output or inflation. In Panel B, we regress model choice on the share of central bank affiliated authors. The dependent variable is an indicator equal to one if the paper uses a DSGE model, and zero if it uses a VAR model. Controls include the number of authors and the logarithm of three plus the average author experience. $t$-statistics, reported in parentheses, are based on robust standard errors. $p$-values obtained using the wild cluster bootstrap procedure (10,000 repetitions) are reported in square brackets. The unit of observation is the paper.

Panel A: Specification of the Confidence Interval

\begin{tabular}{|c|c|c|c|c|c|c|}
\hline & \multicolumn{3}{|c|}{ Missing CI } & \multicolumn{3}{|c|}{ Narrow or Missing CI } \\
\hline & (1) & (2) & (3) & (4) & (5) & (6) \\
\hline \multirow[t]{3}{*}{ CB Affiliation } & 0.397 & 0.377 & 0.449 & 0.295 & 0.228 & 0.276 \\
\hline & $(2.07)$ & $(1.92)$ & $(2.32)$ & $(1.99)$ & $(1.89)$ & $(2.29)$ \\
\hline & {$[0.056]$} & {$[0.066]$} & {$[0.035]$} & {$[0.087]$} & {$[0.074]$} & {$[0.040]$} \\
\hline Country Dummies & & $\mathrm{X}$ & $\mathrm{X}$ & & $\mathrm{X}$ & $\mathrm{X}$ \\
\hline Controls & & & $\mathrm{X}$ & & & $\mathrm{X}$ \\
\hline Observations & 31 & 31 & 31 & 31 & 31 & 31 \\
\hline$R^{2}$ & 0.121 & 0.213 & 0.264 & 0.167 & 0.320 & 0.488 \\
\hline \multicolumn{7}{|c|}{ Panel B: Choice of the Model (DSGE vs. VAR) } \\
\hline & \multicolumn{2}{|c|}{ (1) } & \multicolumn{2}{|c|}{$(2)$} & \multicolumn{2}{|c|}{$(3)$} \\
\hline \multirow[t]{3}{*}{ CB Affiliation } & \multicolumn{2}{|c|}{0.363} & \multicolumn{2}{|c|}{0.296} & \multicolumn{2}{|c|}{0.319} \\
\hline & \multicolumn{2}{|c|}{$(2.27)$} & \multicolumn{2}{|c|}{$(1.71)$} & \multicolumn{2}{|c|}{$(1.80)$} \\
\hline & \multicolumn{2}{|c|}{$[0.032]$} & \multicolumn{2}{|c|}{ [0.103] } & \multicolumn{2}{|c|}{$[0.090]$} \\
\hline \multicolumn{3}{|l|}{ Country Dummies } & \multicolumn{2}{|c|}{$\mathrm{X}$} & \multicolumn{2}{|c|}{$\mathrm{X}$} \\
\hline \multicolumn{5}{|l|}{ Controls } & \multicolumn{2}{|c|}{$\mathrm{X}$} \\
\hline Observations & \multicolumn{2}{|c|}{50} & \multicolumn{2}{|c|}{50} & \multicolumn{2}{|c|}{50} \\
\hline$R^{2}$ & \multicolumn{2}{|c|}{0.087} & \multicolumn{2}{|c|}{0.155} & \multicolumn{2}{|c|}{0.170} \\
\hline
\end{tabular}




\section{Appendix}

\section{Table A.1: Dictionary for Tone Analysis}

The table presents our dictionary of positive and negative adjectives used to classify the tone of the paper's abstract and conclusion. The positive adjectives are ordered by the number of times they occur in the abstracts and conclusions of the papers in the sample. The negative adjectives are paired up with their positive counterparts whenever possible.

\begin{tabular}{ll}
\hline \hline Positive & Negative \\
\hline significant & insignificant \\
large & small \\
effective & ineffective \\
important & unimportant \\
considerable & limited \\
major & minor \\
strong & weak \\
robust & modest \\
useful & useless \\
powerful & powerless \\
substantial & marginal \\
desirable & undesirable \\
certain & uncertain \\
successful & unsuccessful \\
meaningful & meaningless \\
sizable & little \\
desired & \\
extraordinary & \\
big & tiny \\
huge & negligible \\
non-negligible & low \\
high & \\
beneficial & \\
\hline \hline
\end{tabular}




\section{Table A.2: Variable Descriptions}

\begin{tabular}{|c|c|}
\hline Var & escription \\
\hline \multicolumn{2}{|l|}{ Dependent variables } \\
\hline Peak effect on output & $\begin{array}{l}\text { The maximum impact of the QE program shock on the level of output (i.e., real } \\
\text { GDP or industrial production). The variable is expressed in percent. }\end{array}$ \\
\hline $\begin{array}{l}\text { Cumulative effect on out- } \\
\text { put }\end{array}$ & $\begin{array}{l}\text { The impact of the QE program shock on the level of output (i.e., real GDP or } \\
\text { industrial production) at the end of the time period studied. The variable is } \\
\text { expressed in percent. }\end{array}$ \\
\hline $\begin{array}{l}\text { Standardized peak effect } \\
\text { on output }\end{array}$ & $\begin{array}{l}\text { The maximum impact of the QE shock on the level of output (i.e., real GDP or } \\
\text { industrial production), using a QE shock size equivalent to } 1 \% \text { of the country's } \\
\text { GDP prior to QE. The variable is expressed in percent. }\end{array}$ \\
\hline $\begin{array}{l}\text { Standardized cumulative } \\
\text { effect on output }\end{array}$ & $\begin{array}{l}\text { The impact of the QE shock on the level of output (i.e., real GDP or industrial } \\
\text { production) at the end of the time period studied, using a QE shock size equivalent } \\
\text { to } 1 \% \text { of the country's GDP prior to QE. The variable is expressed in percent. }\end{array}$ \\
\hline Peak effect on inflation & $\begin{array}{l}\text { The maximum impact of the QE program shock on the level of prices (i.e., CPI). } \\
\text { The variable is expressed in percent. }\end{array}$ \\
\hline $\begin{array}{l}\text { Cumulative effect on infla- } \\
\text { tion }\end{array}$ & $\begin{array}{l}\text { The impact of the QE program shock on the level of prices (i.e., CPI) at the end } \\
\text { of the time period studied. The variable is expressed in percent. }\end{array}$ \\
\hline $\begin{array}{l}\text { Standardized peak effect } \\
\text { on inflation }\end{array}$ & $\begin{array}{l}\text { The maximum impact of the QE shock on the level of prices (i.e., CPI), using a } \\
\text { QE shock size equivalent to } 1 \% \text { of the country's GDP prior to QE. The variable } \\
\text { is expressed in percent. }\end{array}$ \\
\hline $\begin{array}{l}\text { Standardized cumulative } \\
\text { effect on inflation }\end{array}$ & $\begin{array}{l}\text { The impact of the QE shock on the level of prices (i.e., CPI) at the end of the } \\
\text { time period studied, using a QE shock size equivalent to } 1 \% \text { of the country's GDP } \\
\text { prior to QE. The variable is expressed in percent. }\end{array}$ \\
\hline $\begin{array}{l}\text { Statistical significance of } \\
\text { output }\end{array}$ & $\begin{array}{l}\text { Indicator equal to one if the authors state that the peak effect of the QE shock } \\
\text { on either the level of output or on output growth is positive and statistically } \\
\text { significant, and zero otherwise. If the authors do not make explicit statements } \\
\text { about statistical significance, we use the confidence intervals reported in the paper. }\end{array}$ \\
\hline $\begin{array}{l}\text { Economic significance of } \\
\text { output }\end{array}$ & $\begin{array}{l}\text { Variable equal to one if the authors state that the estimated effect of the QE shock } \\
\text { on either the level of output or on output growth is economically significant; zero } \\
\text { if the effect is stated to be economically insignificant or small; and } 0.5 \text { if the effect } \\
\text { is stated to be somewhat economically significant. }\end{array}$ \\
\hline $\begin{array}{l}\text { Statistical significance of } \\
\text { inflation }\end{array}$ & $\begin{array}{l}\text { Indicator equal to one if the authors state that the peak effect of the QE shock } \\
\text { on either the level of prices or on the inflation rate is positive and statistically } \\
\text { significant, and zero otherwise. If the authors do not make explicit statements } \\
\text { about statistical significance, we use the confidence intervals reported in the paper. }\end{array}$ \\
\hline $\begin{array}{l}\text { Economic significance of } \\
\text { inflation }\end{array}$ & $\begin{array}{l}\text { Variable equal to one if the authors state that the estimated effect of the QE shock } \\
\text { on either the level of prices or on the inflation rate is economically significant; zero } \\
\text { if the effect is stated to be economically insignificant or small; and } 0.5 \text { if the effect } \\
\text { is stated to be somewhat economically significant. }\end{array}$ \\
\hline $\begin{array}{l}\text { Share of positive adjec- } \\
\text { tives in abstract }\end{array}$ & $\begin{array}{l}\text { Share of positive adjectives out of all adjectives in the article's abstract, using the } \\
\text { dictionary of positive adjectives from Table A.1. }\end{array}$ \\
\hline
\end{tabular}

Continued on next page 
Table A.2 - continued

\begin{tabular}{|c|c|}
\hline Variable & Description \\
\hline $\begin{array}{l}\text { Share of negative adjec- } \\
\text { tives in abstract }\end{array}$ & $\begin{array}{l}\text { Share of negative adjectives out of all adjectives in the article's abstract, using the } \\
\text { dictionary of negative adjectives from Table A.1. }\end{array}$ \\
\hline $\begin{array}{l}\text { Sentiment score in ab- } \\
\text { stract }\end{array}$ & $\begin{array}{l}\text { Share of positive adjectives out of all adjectives in the article's abstract minus the } \\
\text { share of negative adjectives out of all adjectives in the article's abstract. We use } \\
\text { the dictionary of positive and negative adjectives from Table A.1. }\end{array}$ \\
\hline Missing CI & $\begin{array}{l}\text { Indicator equal to one if the paper does not report a confidence interval or the } \\
\text { statistical threshold used to assess statistical significance, and zero otherwise. }\end{array}$ \\
\hline Narrow or Missing CI & $\begin{array}{l}\text { Indicator equal to one if (i) the paper does not report a confidence interval or the } \\
\text { statistical threshold used to assess statistical significance or (ii) the paper uses a } \\
68 \% \text { confidence interval, and zero otherwise. }\end{array}$ \\
\hline Model & $\begin{array}{l}\text { Indicator equal to one if the paper uses a DSGE model, and zero if it uses a VAR } \\
\text { model. }\end{array}$ \\
\hline \multicolumn{2}{|l|}{ Main independent variables } \\
\hline CB affiliation & $\begin{array}{l}\text { The share of authors who are affiliated with a central bank at the time of the } \\
\text { paper's first public circulation, as determined by our search in the summer of } \\
\text { 2019. Authors who are affiliated with the BIS are treated as } 0.5 \text { central bankers. }\end{array}$ \\
\hline Max seniority & $\begin{array}{l}\text { The numerical rank of the most senior author. We convert job titles into numerical } \\
\text { ranks using the dictionary from Table A.3. }\end{array}$ \\
\hline German CB & $\begin{array}{l}\text { Indicator equal to one if at least one of the authors is employed at the Bundesbank, } \\
\text { and zero otherwise. }\end{array}$ \\
\hline Other EA CB & $\begin{array}{l}\text { Indicator equal to one if at least one of the authors is employed at the ECB or at } \\
\text { a euro area national central bank that is not the Bundesbank, and zero otherwise. }\end{array}$ \\
\hline Non EA CB & $\begin{array}{l}\text { Indicator equal to one if at least one of the authors is employed at a central bank } \\
\text { outside of the euro area or at the BIS, and zero otherwise. }\end{array}$ \\
\hline \multicolumn{2}{|l|}{ Control variables } \\
\hline Author experience & $\begin{array}{l}\text { The number of years since the author's highest obtained educational degree, aver- } \\
\text { aged across all authors of the paper. }\end{array}$ \\
\hline Number of authors & The number of authors of the paper. \\
\hline
\end{tabular}




\section{Table A.3: Dictionary of Job Titles to Numerical Ranks}

The table presents the dictionary used to convert job titles into numerical ranks.

\begin{tabular}{ll}
\hline \hline Rank & Job title \\
\hline \multicolumn{2}{l}{ Central Bankers } \\
1 & Researcher, economist, PhD economist, research associate/economist, expert \\
2 & Senior researcher, analyst, research economist or economist \\
3 & Principal/lead researcher or economist \\
4 & (Senior) Adviser \\
5 & Deputy Director/Head of Section/Team head/Manager \\
6 & (Senior) Director, Head, Chief economist, (Vice) President, Senior manager, Deputy Governor \\
& \\
Academics \\
2 & Post-doc, lecturer, PhD Student \\
3 & Assistant professor \\
4 & Fssociate professor \\
\hline \hline
\end{tabular}

